\title{
Crowdwork Platform Governance toward Organizational Value Creation
}

\begin{abstract}
Crowdwork, a new form of digitally mediated employment and part of the so-called gig economy, has the capacity to change the nature of work organization and to provide strategic value to workers, job providers, and intermediary platform owners. However, because crowdwork is temporary, large-scale, distributed, and mediated, its governance remains a challenge that often casts a shadow over its strategic value. The objective of this paper is to shed light on the making of value-adding crowdwork arrangements. Specifically, the paper explores crowdwork platform governance mechanisms and the relationships between these mechanisms and organizational value creation. Building on a comprehensive review of the extant literature on governance and crowdwork, we construct an overarching conceptual model that integrates control system and coordination system as two complementary mechanisms that drive crowdwork platform governance effectiveness and the consequent job provider benefits. Furthermore, the model accentuates the role of the degree of centralization and the degree of routinization as critical moderators in crowdwork platform governance. Overall, the paper highlights the potential of crowdwork to contribute not only to inclusion, fair wages and flexible work arrangements for workers but also to organizations' value and competitive edge.
\end{abstract}

Keywords: Crowdwork, Governance, Organizational Value, Gig Economy, Work Organization, Centralized Platforms, Decentralized Platforms, Literature Review 


\section{Introduction}

Paid, online crowdwork ${ }^{1}$ has emerged as a new model of digitally mediated employment. It encompasses all kinds of remunerated work organized via online labor platforms, which function as online marketplaces that enable job providers to look for workers and help job seekers to find work (Kittur et al., 2013). This paper sheds light on the mechanics of crowdwork platforms and theorizes on the relationship between crowdwork platform governance and organizational value.

Crowdwork is expected to contribute to innovation, strategic competitive advantage, and reduction of labor costs by giving organizations flexible access to a large pool of resourceful and (usually cheap) labor on a temporary basis. Platforms such as Amazon's Mechanical Turk (AMT) and Upwork play an essential role in crowdwork arrangements, facilitating the transactions and interactions between workers and job providers. For workers across the globe, crowdwork has the potential to unlock previously unthinkable career opportunities in online marketplaces (Marr, 2016). However, crowdwork can be a double-edged sword, as it can both enhance and diminish the quality of workers' lives (Deng et al., 2016). Furthermore, in terms of strategic value for job providers, the low cost of labor, with limited or no worker protections, may provide short-term benefits but may not be sustainable in the long term (Kittur et al., 2013). Nevertheless, crowdwork is disrupting the working arrangements that already endure major shifts in contemporary business organizations (Forman et al., 2014).

There are three key stakeholders in crowdwork: workers, organizations or individuals providing work (job providers or employers ${ }^{2}$ ) and intermediary platforms (online marketplaces). Getting value out of crowdwork is challenging for all three stakeholders for various reasons. Workers' high dropout rates

\footnotetext{
${ }^{1}$ Crowdwork and crowdsourcing are often used interchangeably in the literature. We use the term crowdwork because we focus exclusively on paid labor, whereas crowdsourcing often relies on volunteers (e.g., in emergencies) (Liu, 2014). Moreover, in this paper, crowdwork only refers to work performed by workers external to the job provider's organization.

${ }^{2}$ Crowdworkers are self-proprietors (i.e., they are not employees in a legal sense). However, crowdworkers often still act like parties to an employment contract (Chen and Horton, 2016).
} 
due to low wages or unfair treatment, which have been studied extensively (Deng et al., 2016; Ma et al., 2016), threaten the long-term viability of the crowdwork industry. From a legal perspective, major problems lie in categorizing the relationships between the job provider, platform and worker (Donini et al., 2017). From an organizational point of view, crowdwork comprises the changing of permanent jobs into a supple resource pool in which crowdworkers assume tasks in a project-based manner (Durward et al., 2016). There is a risk of losing knowledge and control over the crowd's activities, not just because the work is distributed and temporary, but also because of the intermediary platforms. Many of these challenges can be traced to how crowdwork platforms operate - temporary work arrangements, scalable and distributed workforce, and technology-mediated activities - which make crowdwork platform governance difficult. Platform governance consists of two aspects: governance of and governance by platforms (Gillespie, 2017). The first aspect refers to the rules that platforms need as an intermediary, while the second aspect refers to the platforms' ability to mediate between sides, moderate content, coordinate and control the workflow (Gillespie, 2017). This paper focuses on the latter, and thus we use the term crowdwork platform governance throughout the rest of this paper to denote the responsibility of platforms as mediators of temporary and distributed work arrangements between job providers and workers.

Governance is often mentioned in studies of crowdwork but remains poorly defined. In broad terms, crowdwork platform governance refers to various control and coordination systems, including work practices, standards and policies (Deng et al., 2016, p. 281) with regard to, for example, task design, feedback from clients or platforms, financial and/or social incentives, and quality management (Schörpf et al., 2017, p. 46). However, a review of the literature reveals a dearth of systematic studies of crowdwork platform governance mechanisms. Furthermore, the crowdwork phenomenon is in the infancy stage, with related practices still forming and socio-technical processes remaining flexible (Nickerson, 2014). Consequently, Information Systems (IS) scholars have an opportunity to contribute to understanding and designing the social and technical foundations of crowdwork. 
Accordingly, this paper aims, first, to contribute to a better understanding of crowdwork platform governance and, subsequently, to address some of the most pressing challenges that job provider organizations face in attempting to extract value from crowdwork. Particularly, while extant research differentiates between creative and routine crowdwork (Buettner, 2015; Margaryan, 2016), it is unclear whether and how routine and creative crowdwork are governed differently by platforms and how this may impact the value generation to job providers. Similarly, while research increasingly recognizes that governance by crowdwork platforms may be done in either a centralized or a decentralized manner (Atzori, 2015; Hein et al., 2016), it is unclear how different governance mechanisms function under centralized and decentralized crowdwork platform governance modes. Thus, for organizations making the decision to use crowdwork as part of their employment strategy, knowledge and choices regarding crowdwork platform governance are critical (Nickerson et al., 2017).

With this in mind, in the present review paper, we focus on understanding, revealing, and synthesizing the key constructs at play in the literature and theoretically reflecting on governance issues in crowdwork platforms by addressing the following research question: What is the relationship between crowdwork platform governance mechanisms and organizational value creation? To answer this overall question, we must also clarify what the crowdwork platform governance mechanisms are. We analyze the crowdwork literature to elicit how governance has been investigated and conceptualized. The paper focuses on crowdwork systems from the job provider's perspective, examining the opportunities and challenges for organizational value creation. We contribute to the domain of crowdwork by introducing a conceptual model of crowdwork platform governance that is also suitable for alternative, decentralized crowdwork arrangements and for both routine and creative crowdwork platforms. Practically, the suggested model provides a basis to specifying guidelines for crowdwork, enabling organizations to take advantage of the potentials of crowdwork while also establishing fair working conditions for individual crowdworkers (Durward et al., 2016). 


\section{Theoretical Foundations}

This section lays the groundwork for the examination of crowdwork platform governance. It introduces crowdwork platforms as a specific case of multi-sided platforms and covers the conceptual foundations for the study of crowdwork platform governance.

\subsection{Multi-sided Platforms}

Crowdwork platforms may be considered an instance of multi-sided platforms (Schmidt, 2017), functioning as online markets that facilitate exchange among various types of stakeholders who are not otherwise able to transact with each other (Gawer, 2014). For example, Airbnb and eBay enable interactions between two or more separate sides through the platform (Hagiu and Wright, 2015). Upwork provides independent workers from around the world the ability to connect with and offer their services (e.g., programming skills) to job providers. The exchanges facilitated by the platform are usually one-off transactions.

Overall, the platform plays an intermediary role to coordinate the supply and demand aspects of a market (Schmidt, 2017). The platforms tend to move most of the expenses, risks and responsibilities to the other parties, and they usually only provide a virtual service such as an app or a website and do not support the labor cost or the production means (Schmidt, 2017). At the same time, the platforms uphold sole and privileged control over data, processes and rules on the platform. The services and tasks are coordinated via the platform but are not necessarily bound to a precise place and specific person. Thus, these kinds of platforms are often location-independent and support distributed actions as well as a high degree of scalability. These characteristics of multi-sided platforms - mediation between distributed sides, temporary arrangements, and scalability - are mirrored in the characteristics of crowdwork that is performed through platforms. 


\subsection{Crowdwork}

Crowdwork includes all types of paid work organized via online labor platforms (De Stefano, 2016; Donini et al., 2017). These platforms function as intermediaries between workers and job providers, facilitating the description, submission, acceptance and payment for the work accomplished (Irani, 2015a). AMT, Upwork, TopCoder, CrowdFlower, and Clickworker are some examples of crowdwork platforms (Margaryan, 2016).

The nature of tasks on crowdwork platforms can differ noticeably. Research distinguishes between microwork (i.e., more routine crowdwork) and online freelancing (i.e., more creative crowdwork) (De Stefano, 2016; Margaryan, 2016). ${ }^{3}$ Microwork includes projects divided into microtasks that can be performed in seconds or minutes, are generally repetitive, and do not require a high level of skill (e.g., filling out surveys, tagging pictures) (De Stefano, 2016). Microtasks are defined as "stand-alone tasks" with a "clear definition" (Buettner, 2015, p. 4611). Amazon's Mechanical Turk (AMT) is the best-known example of a microwork or routine crowdwork platform.

In contrast, creativity fundamentally involves innovative performance (Woodman et al. 1993). Creative tasks include idea creation, competition, and evaluation that can be accomplished by the crowd (Buettner, 2015). As such, creative work often requires significantly more resources (e.g., skills and time) than routine work at individual, team, and organizational levels (Rimmer, 2016). Online freelancing is a good example of more creative crowdwork. In this case, job providers contract skilled services, such as graphic design and web development, to dispersed workers (Margaryan, 2016).

\footnotetext{
${ }^{3}$ The degree of routinization and the degree of creativity of work are two anchors on a continuum that characterize the complexity of work tasks and the consequent skill level required to accomplish it. However, in this paper, we make a dichotomous distinction between routine and creative crowdwork to coincide with the noticeable difference between the crowdwork platforms that focus on routine microtasks (e.g., AMT) and the platforms that focus on creative freelancing (e.g., TopCoder). Thus, we presume that routine crowdwork implies non-creative work, and similarly, that creative crowdwork implies non-routine work.
} 
Upwork (previously oDesk and Elance) is an example of an online freelancing or creative crowdwork platform (Margaryan, 2016).

Crowdwork platforms provide a governance structure that is necessary to address the challenges in managing a distributed and scalable workforce (Deng et al., 2016; Greengard, 2011) performing tasks that have traditionally been handled by small, dedicated groups in organizations (e.g., Deng et al., 2016; Kittur et al. 2013). Crowdwork platforms govern the work process (e.g., instruction, configuration, task assignment) to drive participation of workers and improve worker productivity (Deng et al., 2016). Both unclear task descriptions and complex interfaces can impact the quality of work negatively, because workers are uncertain of the correct procedures and expectations (Kittur et al., 2013). As task complexity increases, the governance of the work process can be expected to become more challenging.

In sum, the factors that impact crowdwork success and the value generated for job providers are both platform- and work-related and are often difficult to separate. As online, paid crowdwork only exists and functions because it is performed via a platform, we contend that crowdwork governance is crowdwork platform governance. Specifically, it is the governance by platforms of temporary, scalable, distributed and mediated work arrangements between job providers and workers - as will be discussed in the next section.

\subsection{Crowdwork Platform Governance}

It is necessary for multi-sided platforms to attract, coordinate and control the respective parties participating in the platform (Schreieck et al., 2016). Crowdwork platforms, specifically, have been argued to provide general directive control through the standards, policies and rules that guide behavior on the platform (Deng et al., 2016; Manner et al., 2012) and allow the monitoring of workers' and job providers’ performance and environment (Howcroft and Bergvall-Kåreborn, 2018). Furthermore, crowdwork platforms coordinate the interactions among job providers and workers (Howcroft and 
Bergvall-Kåreborn, 2018; Schmidt, 2017). Thus, crowdwork platform governance rests on two key aspects: control and coordination.

In multi-sided platforms, control includes the ways that the platform owner monitors and oversees the processes inside the platform (Schmidt, 2017). Having access to data on all interactions enables platform owners to have the power to affect the exchange among the parties (Schreieck et al., 2016). The well-known control strategies of formal and informal control (Eisenhardt, 1985) are utilized in crowdwork platforms through mechanisms such as quality control and reputation control (Schreieck et al., 2016). Formal control is performed via performance evaluation (Eisenhardt, 1985), with behavior and outcome evaluation being the two common modes of formal control. In behavior control, controllers monitor controlees' behaviors and reward them according to the degree to which they follow the procedures (Kirsch, 1997). In outcome control, controllers evaluate performance and grant rewards in relation to outcomes achieved, not procedures followed (Eisenhardt, 1985). Informal control, conversely, can be reached by minimizing the divergence of preferences between organizational members (Eisenhardt, 1985). In this case, members collaborate in the accomplishment of organizational goals because they have internalized these goals. Internalization of goals may be achieved through a variety of informal control mechanisms such as affirmative human resource policies, training, team building, and socialization (Kirsch, 1997).

Coordination in crowdwork platforms includes mechanisms for attracting both job providers and workers (cf. Hagiu and Spulber, 2013) through managing dependencies between crowdwork activities (based on Crowston, 1997; Malone and Crowston, 1994; Kittur et al., 2013). While coordination refers to "the act of working together harmoniously" (Malone and Crowston, 1990, p. 5), in classic organizational research, coordination and control are often entangled and are not always easy to distinguish. For example, Mintzberg (1980) discusses five ways to facilitate coordination; however, some of these (direct supervision, outputs standardization and work process standardization) overlap with formal control mechanisms, while others (skills standardization) overlap with informal control 
mechanisms. Only one - mutual adjustment, in which workers coordinate their activities via informal communication with each other (Mintzberg, 1980) - truly functions as a coordination method. Coordination methods are selected to manage dependencies among tasks and resources that exist in the process (Crowston, 1997). For example, in crowdwork platforms, complex jobs require task decomposition into subtasks, where two or more workers may be working on the same task or consecutive tasks, setting limitations on their actions and demands on their interactions with each other (cf. Kittur et al., 2013). To solve these coordination problems, platforms must engage in additional activities not captured in formal and informal controls.

In the next section, we introduce the distinction between centralized and decentralized governance - a theoretically and practically significant factor to consider in crowdwork platform governance given the increased attention in the discourse to distributed architectures, such as peer-topeer networks and blockchain technology, which rapidly gain traction across industries and provide an infrastructure for a new form of decentralized crowdwork platforms (Tate et al., 2017; Xu et al., 2016).

\subsubsection{Centralized and Decentralized Crowdwork Platform Governance}

The overwhelming majority of research on crowdwork and its governance assumes that crowdwork arrangements are, by design, limited to configurations of workers, employers and centralized intermediary platforms, such as AMT (Vakharia and Lease, 2015). However, recent research has highlighted that crowdwork as a concept could go beyond traditional centralized arrangements by drawing on ideas of cooperativism and worker-owned and -managed platforms (Gaikwad et al., 2015; Scholz, 2016).

Centralized and decentralized modes of crowdwork platform governance are likely to apply different control and coordination mechanisms in the platform, which subsequently may have different advantages and disadvantages (Hein et al., 2016). Centralized crowdwork platform governance is expected to enable smooth coordination of workflows on highly separate tasks through central guidance 
and direction (based on King, 19834). There is a high level of control over work process and output standards (Brown and Grant, 2005), which enables control over work quality and crowdworker behavior through monitoring and assessment against standards (based on King, 1983). Centralized crowdwork platform governance is known to effectively keep performance in line with platform protocols and procedures (King, 1983). Thus, centralization has clear advantages.

However, centralization also has adverse side effects that stem from power concentration, such as dishonesty, discrimination, protection of status and misuse of power (Zyskind et al., 2015). In crowdwork platforms, a centralized governance means a lack of direct communication among workers and job providers, because all communications are mediated via the platform (Kittur et al., 2013). Thus, mutual adjustment among workers is hindered. Moreover, centralization of all decision-making (Brown and Grant, 2005) may lead to inefficiencies due to a lack of capacity and flexibility, which, in turn, may lead to insufficient responsiveness to challenges (Atzori, 2015). The high level of control exerted on participants during interactions and on the accessibility of workers to the platform also means there is often little transparency in governance processes (Hein et al., 2016).

In comparison, decentralization of governance removes hierarchical power structures in organizations and, therefore, can decrease the misuse of power (Azfar et al., 2001; Zyskind et al., 2015). Decentralized crowdwork platform governance can improve efficiency by removing decision-making bottlenecks; can improve fairness, democracy, self-determination, and accountability by distributing decision-making rights and responsibilities; and can increase participation, ownership and obligation by all participants (based on Azfar et al., 2001; Brown and Grant, 2005). When work is more complex, decentralized crowdwork platform governance is likely to allow for smoother coordination of workflows, as overlapping tasks and parallel working requires cooperation among workers, worker

\footnotetext{
${ }^{4}$ King (1983) discusses the organizational considerations of centralized and decentralized computing in general, not specifically as applied to crowdwork platform governance. We have adapted his arguments to the context of crowdwork platform governance.
} 
discretion and less central oversight (King, 1983). Moreover, decentralized arbitration systems within the platform can address conflicts via smart contracts, with rules agreed upon by the parties and matched with common law (Atzori, 2015). Furthermore, decentralized crowdwork platform governance provides an opportunity for direct communication among workers and between workers and job providers (based on Atzori, 2015).

At the same time, decentralization can, paradoxically, remove behaviors and institutions that are vital to high-quality work (Whiting et al., 2016). Decentralization poses serious control and coordination challenges and creates demands for laborious consensus-based decision making. In decentralized governance, each platform stakeholder may potentially require different sets of controls and standards (Brown and Grant, 2005). Decentralized crowdwork platform governance can be expensive, because it requires creating and maintaining means to cater for the various parties' opinions. Thus, there are substantial costs involved in applying well-developed decentralized plans (King, 1983). Incentives must be considered for managers, data processing experts, and members to pursue the creation of such a plan. As such incentives are not always readily available, a gradual development toward the decentralization of crowdwork platform governance may be appropriate (King, 1983). A summary of the differences between centralized and decentralized platform governance is presented in Table 1.

\section{Table 1}

Centralized Crowdwork Platform Governance vs. Decentralized Crowdwork Platform Governance

\begin{tabular}{lll}
\hline & $\begin{array}{l}\text { Centralized Crowdwork Platform (CP) } \\
\text { Governance }\end{array}$ & $\begin{array}{l}\text { Decentralized Crowdwork Platform (CP) } \\
\text { Governance }\end{array}$ \\
\hline $\begin{array}{l}\text { Workflow } \\
\text { Coordination }\end{array}$ & $\begin{array}{l}\text { Central guidance and direction provide } \\
\text { smoother coordination of workflow in } \\
\text { discrete tasks (King, 1983). }\end{array}$ & $\begin{array}{l}\text { Worker discretion and distributed oversight } \\
\text { provide smoother coordination of workflow in } \\
\text { parallex projects, where tasks overlap and } \\
\text { workers are needed (King, 1983). }\end{array}$ \\
\hline
\end{tabular}




\begin{tabular}{|c|c|c|}
\hline Communication & $\begin{array}{l}\text { There is no direct communication between } \\
\text { workers and job providers (all } \\
\text { communication is mediated by the central } \\
\text { platform) (Kittur et al., 2013). }\end{array}$ & $\begin{array}{l}\text { There is an opportunity for direct } \\
\text { communication among all platform participants } \\
\text { (e.g., workers, job providers) (Atzori, 2015). }\end{array}$ \\
\hline Decision Making & $\begin{array}{l}\text { Decision making power is concentrated in } \\
\text { the platform. The platform exercises a high } \\
\text { level of control on whether and how workers } \\
\text { and job providers can access the platform, } \\
\text { and there is a lack of transparency in } \\
\text { governance processes (Hein et al., 2016). }\end{array}$ & $\begin{array}{l}\text { Decision making power is distributed among all } \\
\text { stakeholders. The platform's control on workers } \\
\text { and job providers is loosened, and the } \\
\text { governance process is more transparent (Atzori, } \\
\text { 2015; Hein et al., 2016; Zyskind et al., 2015). }\end{array}$ \\
\hline Standardization & $\begin{array}{l}\text { The same set of standards guide all } \\
\text { stakeholders' behaviors on the platform } \\
\text { (Brown and Grant, 2005). }\end{array}$ & $\begin{array}{l}\text { Different customized standards may guide the } \\
\text { behavior of different stakeholders (Brown and } \\
\text { Grant, 2005). }\end{array}$ \\
\hline Control Cost & $\begin{array}{l}\text { Cost of control is reduced, as the same rules } \\
\text { are applied to all parties (Bergvall-Kåreborn } \\
\text { and Howcroft, 2014; King, 1983). }\end{array}$ & $\begin{array}{l}\text { Cost of control is high, either because of efforts } \\
\text { required to carry out control of various } \\
\text { stakeholders with different interests and power } \\
\text { or errors that happen due to no control (King, } \\
\text { 1983). }\end{array}$ \\
\hline Quality Control & $\begin{array}{l}\text { The platform controls workers' submission } \\
\text { adherence to platform standards through } \\
\text { monitoring (King, 1983, p. 20). }\end{array}$ & $\begin{array}{l}\text { Consensus-based evaluation of quality controls } \\
\text { workers' submission adherence to collectively } \\
\text { agreed-upon standards. Incentives for different } \\
\text { parties to keep to these commitments are needed } \\
\text { (King, 1983). }\end{array}$ \\
\hline $\begin{array}{l}\text { Performance } \\
\text { Control }\end{array}$ & $\begin{array}{l}\text { Algorithms keep performance in line with the } \\
\text { platform's protocols and standards (King, } \\
\text { 1983). }\end{array}$ & $\begin{array}{l}\text { Workers' discretion, self-regulation and } \\
\text { informal control keep performance in line with } \\
\text { the prevailing standards (King, 1983, p. 3). }\end{array}$ \\
\hline
\end{tabular}

This concludes the groundwork for the literature review and conceptual model development.

Above, we have clarified our approach to crowdwork platform governance. First, we considered crowdwork platforms as a specific case of multi-sided platforms. Second, we considered crowdwork platform governance as a matter of control and coordination of platform resources and activities. These conceptual clarifications guided the literature review, as outlined below.

\section{Methodology}


Research on crowdwork is growing, and much of it has been conducted outside the Information Systems (IS) field. Due to the vastness of the crowdwork literature, we limited the initial sample of studies in the literature review to those in which both crowdwork platform and governance were central themes. Overall, we conducted a state-of-the-art theory development review that aimed to examine how crowdwork platform governance is conceptualized and practiced, as well as to explore potential theoretical extensions thereof. Accordingly, we used a theoretical review strategy (Paré et al., 2015) to analyze the literature in our search for themes and patterns with respect to crowdwork platform governance.

The review covers conceptual and empirical papers in journals and conferences, both within and outside the IS field, that reveal a diversity of patterns concerning how crowdwork platform governance is conceptualized and studied, as summarized in Appendix (Table A.1, A.2 and A.3). We used the data in the Appendix as the basis for a subsequent analysis to identify themes in crowdwork platform governance research as well as to reveal perceived gaps and directions for future research. Broadly, we followed the approach of Webster and Watson (2002) to develop literature-based concept matrices that render the thematic terrain. Next, we followed the approach of Rowe (2014) to develop a conceptual model that portrays the relationships among concepts.

\subsection{Literature Search}

In order to identify relevant literature for this study, we applied the recommendations of Webster and Watson (2002) and Rowe (2014). We used a comprehensive collection of scientific databases as the primary data source: EBSCO, Proquest, ACM DL, Scopus, Google Scholar, AISeL and IEEE Xplore. We searched for titles, keywords, abstracts, and full texts using the following combinations of search terms: ("crowdwork" OR "crowdsource" OR "crowdworker") AND "governance”; (“job provider” OR “job requester”) AND "governance”; (“digital labor” OR “digital labor platform” OR “online digital market*” OR “Amazon Mechanical Turk”) AND “governance”. This 
procedure ensured that the initial sample of studies included only those articles in which both crowdwork and governance were important themes. We included AMT (with spelling variations) as a specific crowdwork platform, because this platform is the most frequently studied. Aiming for high-quality publications, we began by focusing on papers from the AIS Senior Scholars' Basket ${ }^{5}$ and designated IS conferences. We then extended the search scope to adjoining disciplines, such as computer science, social sciences, economics and finance, and law, as well as IEEE and ACM conferences. Within those disciplines, we eliminated publications not considered research papers, such as editorials, interviews, commentaries, book reviews and keynotes.

Next, we selected a set of relevant research papers by going through each paper's abstract and skimming the entire content. We considered only papers on paid crowdsourcing and paid crowdwork, while we excluded papers on unpaid crowdsourcing. Moreover, we only kept papers that explicated crowdwork platform governance in some detail, excluding papers that only mentioned the term "governance" but did not examine the phenomenon. Because the worker perspective heavily dominates the crowdwork literature, we made a choice to only focus on highly cited or review papers from the worker perspective. For example, there are many papers on the motivations of crowdworkers as well as on their legal status; of these, we selected only a few that (a) represented the majority of arguments made or (b) made alternative, but theoretically interesting arguments.

Finally, when a number of relevant papers had been identified, we utilized a snowballing approach to make sure we had not missed an essential source (Wohlin, 2014). This approach resulted in a final sample of 78 relevant papers discussing crowdwork platform governance and value to job providers.

\footnotetext{
5 See https://aisnet.org/?SeniorScholarBasket.
} 


\subsection{Analysis}

Based on the review of the relevant literature, we first generated a classification of previous studies based on their overall focus and perspective on crowdworkers, job providers and the platform (Table A.1 in the appendix provides example papers, with further references provided in Table A.4). Most papers on crowdwork platform governance focus on the worker perspective (Nickerson, 2014), with less emphasis on the perspectives of the job provider and the platform. However, many papers discuss crowdwork from more than one agent's perspective, typically focusing on either the worker and the job provider or the worker and the platform. A few papers also provide a holistic perspective by considering the concerns of all three agents (see Table A.1).

Second, we generated a classification of crowdwork platform governance mechanisms by inductively coding the identified papers. We began by identifying all the different potential governance mechanisms mentioned in the papers. The initial list of codes included incentives, reputation, payment rules, decision rights, managing shared resources, managing producer/consumer and task/subtask relationships, contractual rights, sharing information between workers, fairness, transparency, security, accountability, trust, standardization and ethics. We then grouped similar codes and excluded some (e.g., those that were infrequently mentioned and not covered in depth in prior literature, making it difficult to articulate their significance in crowdwork platform governance). Iterating back and forth between the findings and the governance definitions from existing research, we ultimately (a) differentiated between governance mechanisms and the drivers of these mechanisms and (b) postulated two key crowdwork platform governance mechanisms (control and coordination) and three drivers of each mechanism (see Table A.2). Based on the theoretical and practical significance of the degree of routinization of work and the degree of centralization of crowdwork platform governance, we also coded the papers for their focus on routine and creative crowdwork as well as centralized, decentralized and hybrid governance. Notably, we found no papers on purely decentralized crowdwork platform governance, and the majority of papers focus on centralized platform governance of routine crowdwork (Table A.2). 
Third, we analyzed the selected crowdwork papers with an eye towards identifying the value propositions for job providers. The initial list of codes included high quality of work, economic benefit, technological efficiency, job provider anonymity, lack of long-term commitment, scalability, and fast task completion. Again, we grouped similar codes and excluded those that were infrequently mentioned and not covered in depth in prior literature. We converged on five value propositions (Table A.3).

Synthesizing insights from Tables A.1, A.2 and A.3, we identified key themes and gaps in the literature, as described below. We then moved on to develop the conceptual model of crowdwork platform governance to fill the identified gaps.

\section{Prevalent Themes and Gaps in the Literature}

The review revealed two broad themes. The first theme shows that governance by crowdwork platforms is generally achieved through control and coordination mechanisms. There are two important sub-themes here that also reveal two key gaps in the literature: differences between centralized and decentralized platform governance modes and differences between routine and creative crowdwork and its governance. The second theme demonstrates an assumption, prevalent in the literature, that effective crowdwork platform governance can increase the benefits for job providers; however, there is little theoretical or empirical work to support this relationship. We elaborate on each theme below.

\subsection{Theme 1: Crowdwork Platform Governance through Control and Coordination}

A dominant idea in this theme is that crowdwork platform governance consists of control and coordination mechanisms. Control mechanisms, which are critical for running a successful crowdwork platform, include quality control, the reputation system of workers, and the accountability of job providers (Table A.2). Quality control and accountability of job providers are forms of formal control 
(Kirsch, 1997). The former is achieved through direct outcome control (Eisenhardt, 1985), while the latter is achieved through behavior control (Eisenhardt, 1985; Kirsch, 1997), where the rules and procedures set on worker and job provider behavior are expected to lead to specific outcomes. The reputation system of workers, meanwhile, is arguably a form of informal control (Eisenhardt, 1985; Kirsch, 1997) that aligns the goals of job providers, platform owners and workers (i.e., workers strive for higher reputation scores, which controls their behavior in line with the standards set by the platform owner and/or job provider).

Coordination mechanisms are also important for managing a prosperous crowdwork platform and consist of task management, incentive management and contract management (see Table A.2). Task management refers to platforms coordinating the flow of information related to dependencies among tasks (Crowston, 1997), but it can also allow for mutual adjustment between the workers directly (Mintzberg, 1980). Incentive management, meanwhile, refers to the processes of selecting and distributing incentives and rewards (beyond reputation) that motivate workers and job providers (Vakharia and Lease, 2015). Finally, contract management refers to managing the dependencies between types of workers, tasks, and payment rules and conditions (based on Malone and Crowston, 1990). A part of contract management is the selection of workers, which is often a multi-stage process in which workers decide whether to offer their services (based on task description, financial incentives, rumors about job provider, etc.) by submitting bids, and job providers decide which worker(s) to choose based on bid evaluations (Malone and Crowston, 1990).

The review shows that the role of control in crowdwork platform governance receives more research attention than does the role of coordination (Hein et al., 2016; Schreieck et al., 2016). Furthermore, routine and creative crowdwork platforms are increasingly distinguished in the literature, but little is known of how the governance done by platforms differs, or whether it should differ, for routine and creative crowdwork. Moreover, the spreading discourse on blockchain technology drives a growing interest in decentralized platform governance, but the understanding of its benefits and 
challenges is only beginning to emerge (Tate et al., 2017), with no studies on decentralized crowdwork platform governance and only a few studies on hybrid governance. We unpack each of these gaps in the following subsections.

\subsubsection{Centralized and Decentralized Crowdwork Platform Governance}

The dominant idea in this sub-theme is the extent to which crowdwork platform governance (control and coordination) is (or should be) centralized. The logic of the studies in this theme is that the degree of centralization impacts crowdwork platform governance. For example, it has been shown that centralized crowdwork platform governance can improve incentives as well as contract management through centralized decision-making (Whiting et al., 2016). However, the role of control and coordination in centralized and decentralized crowdwork platform governance has not been systematically addressed in existing literature. The review indicates that most existing crowdwork platforms govern centrally, while only a few studies have tried to design and implement single modules inside platforms under decentralized governance (see Table A.2).

\subsubsection{Routine and Creative Crowdwork Platforms}

The dominant idea in this sub-theme is the extent to which crowdwork platforms differ (or do not differ) in design, governance and value proposition depending on the degree of routinization of work. There are different governance challenges in routine and creative crowdwork platforms, such as the lack of job provider accountability, high turnover among workers, and standard quality control (Brawley and Pury, 2016; Deng et al., 2016). The logic of the studies in this theme conveys that these issues are likely to influence the kind of value delivered to job providers, such as the quality of work and the cost of labor. The literature shows an increasing number of studies on creative crowdwork platforms in addition 
to routine platforms (Table A.2). However, little is known regarding the differences between routine and creative crowdwork platform governance, and the kind of value these platforms deliver to job providers.

\subsection{Theme 2: Crowdwork Platform Governance Affects Benefits for Job Providers}

Existing crowdwork research assumes that good governance can improve the value generated by crowdwork for job providers. As shown in Table A.3, crowdwork is strategically vital for organizations (job providers) because it can lower costs and deliver a quick turnaround on tasks (Al-Ani and Stumpp, 2016; Agrawal et al., 2015; Bergvall-Kåreborn and Howcroft, 2014; Brawley and Pury, 2016; Buettner, 2015; Chen and Horton, 2016; Deng and Joshi, 2016; Gould et al., 2016; Gupta et al. 2014; Harris, 2015; Kittur et al., 2013; Rzeszotarski and Kittur, 2012). However, organizations face many challenges in extracting value from crowdwork. For example, a risk of losing control over the activities of workers; challenges related to quality control, reputation inflation and complex task management; and a high churn rate of crowdworkers all threaten the ability of job providers to achieve lower costs and speedy delivery of high-quality results (Deng et al., 2016; Durward et al., 2016; Ma et al., 2016). Many of these challenges appear to be related to governance, but there is a lack of studies explicitly addressing this relationship.

Based on the themes and gaps explicated above, in the following section, we develop a conceptual model of crowdwork platform governance.

\section{Crowdwork Platform Governance: Mechanisms, Drivers and Outcomes}

In the following sections, we develop a conceptual model of crowdwork platform governance (see Fig.1). The central construct of this conceptual model is crowdwork platform governance effectiveness, which refers to the degree to which the control and coordination of platform resources and 
activities help to achieve the desired results (e.g., benefit all stakeholders' interests) (see Table 2 for the definitions of all constructs). Overall, the conceptual model comprises the following components: (1) mechanisms, or the processes through which crowdwork platform governance is realized (i.e., coordination and control); (2) drivers, or the independent variables that drive the control and coordination mechanisms; and (3) value propositions, or the outcomes of crowdwork platform governance in terms of value delivered to job providers. In addition, the model specifies two key moderating effects: (1) the effect that the degree of centralization of crowdwork platform governance has on the relationship between crowdwork platform governance mechanisms and crowdwork platform governance effectiveness; and (2) the effect that the degree of routinization of work has on the relationship between crowdwork platform governance effectiveness and the value propositions delivered to job providers.

\subsection{Mechanisms of Crowdwork Platform Governance Effectiveness}

Based on the literature, we posit that there are two key mechanisms (i.e., processes) through which crowdwork platform governance becomes effective. We label these control and coordination system efficiency (Table A.2). Efficient joint functioning of control and coordination systems is vital for running and managing crowdwork platforms. Control, which comprises formal and informal control, monitors and directs the processes and activities within the platform (Schreieck et al., 2016). Meanwhile, coordination manages the dependencies between crowdwork activities (e.g., between tasks, between workers and job providers) (based on Crowston, 1997; Malone and Crowston, 1994; Kittur et al., 2013).

Control has to do with activities that verify performance outcomes and activities that verify workers' and job providers' compliance with platform standards and policies. Control system efficiency is driven by (1) outcome-oriented formal performance control (Eisenhardt, 1985; Kirsch, 1997), which is established by quality control; (2) informal social control (ibid.), which is established by reputation 
systems of workers; and (3) behavior-oriented formal administrative control (ibid.), which is established by the accountability of job providers.

Coordination has to do with activities that manage the core functionalities of the platform. Coordination system efficiency is driven by (1) task management, which coordinates the workflow, thereby creating individual but interdependent work plans for each worker, as well as opportunities for mutual adjustment (Mintzberg, 1980); (2) incentive management, which coordinates the appropriation of incentives used to motivate workers, align stakeholder interests and complement the informal controls (Vakharia and Lease, 2015); and (3) contract management, which coordinates the formation of agreements between job providers and workers about the terms of work. Contract management is essential for creating actionable work plans and setting ground rules, which form the basis for verification of compliance by the control system (Malone and Crowston, 1990).

\section{[INSERT FIGURE 1 ABOUT HERE]}

\subsubsection{Control System Efficiency}

The purpose of the control system is to ensure that all activities are carried out in accordance with the plan, rectify any mistakes and prevent them from recurring (Fayol, 1949, p. 77). Specifically, in crowdwork, the purpose of managerial control systems is to help reach business goals by facilitating workers' participation and eliciting their best performance (Saxton et al., 2013). Accordingly, we define control system efficiency as the degree to which the crowdwork platform verifies that all activities that are carried out on the platform (e.g., quality assurance) are within the desired range and enables taking corrective actions when needed (see Table 2). For example, quality control is key in driving the verification of work quality and in taking corrective actions (e.g., well-functioning quality control should 
avoid false rejections of work and disgruntled workers). The reputation system drives the verification of crowdworker identity and qualifications and enables taking corrective actions (e.g., ill-qualified workers should be filtered out of the crowdwork platform through low reputation scores) (Horton and Golden, 2015). Accountability of job providers drives the verification of job provider identity and responsibility towards workers, with unscrupulous job providers being filtered out of the platform.

Taken together, an efficient control system (which verifies that all activities carried out on the platform are within the desired range and makes it possible for corrective actions to be taken) positively affects crowdwork platform governance effectiveness. Thus, we posit that:

P1. Control system efficiency has a positive effect on crowdwork platform governance effectiveness.

\subsubsection{Coordination System Efficiency}

The purpose of the coordination system is to handle the core functionalities of the platform and to manage the interdependencies among them. Thus, we define coordination system efficiency as the degree to which the crowdwork platform manages the dependencies among crowdwork activities (e.g., between tasks, between workers and job providers) (Table 2). Coordination in crowdwork platform governance is vital to improving workflows and work output (Gray et al., 2016). For example, managing dependencies between tasks and sub-tasks drives the ability to coordinate large-scale tasks and improves the completion and acceptance rates of such tasks (Chen et al., 2014). Incentive management, meanwhile, manages the dependencies between workers' performance and different types of rewards available to them (Harris and $\mathrm{Wu}, 2014)$. For example, high pricing of tasks lowers the output for the job provider due to budgetary constraints. Conversely, low pricing of tasks results in worker dissatisfaction regardless of reputation earned (Goel et al., 2013). Therefore, managing the dependency between performance and incentives can help balance the limited budget of the job providers and the 
opportunistic behavior of crowdworkers (Goel et al., 2013). Contract management handles the dependencies among job provider, platform and worker. The presence (or absence) of contracts and their conditions is vital in crowdwork platform governance, as different contracts have varying payment structures (Agrawal et al., 2015; Vakharia and Lease, 2015) and place distinct demands on platform and stakeholder resources. Thus, contract management is essential for creating actionable work plans and setting ground rules.

Taken together, an efficient coordination system (that manages the dependencies among crowdwork activities) positively affects crowdwork platform governance effectiveness. Thus, we posit that:

P2. Coordination system efficiency has a positive effect on crowdwork platform governance effectiveness.

\subsection{Drivers of Crowdwork Platform Governance Mechanisms}

Each of the two identified crowdwork platform governance mechanisms (i.e., control and coordination system efficiency) is driven by three key drivers (Table A.2). Control system efficiency is driven by quality control, the reputation system of workers and the accountability of job providers. Coordination system efficiency is driven by task, incentive and contract management. We examine the effect of these drivers on control and coordination system efficiency in the following sections.

\subsubsection{Quality Control}

Quality control refers to the evaluation schemes that assess the degree to which a submitted work meets the set requirements or specifications of a job (Table 2). Quality control enables the assessment of work performance as well as the correction of mistakes in submitted works (Vakharia and 
Lease, 2015). Quality control deals with the algorithms and processes that are applied to assess work quality, as well as with the techniques and methods that are utilized to monitor workers and their accomplishment of work (Vakharia and Lease, 2015). For example, in Clickworker, plagiarism checking, peer review, and testing are utilized to assess work quality (Vakharia and Lease, 2015).

Therefore, quality control that effectively establishes outcome control positively affects the overall control efficiency of crowdwork platform governance by assessing work performance and revealing errors in submitted works. Thus, we posit that:

\section{P3. Quality control has a positive effect on control system efficiency.}

\subsubsection{Reputation System of Workers}

Reputation system of workers refers to the effectiveness of the reputation scheme - that is, the degree to which the system motivates workers to be competent and to comply with the rules of conduct (Table 2). Reputation systems function as an informal social control method that motivates workers' compliant behavior. There are different reputation systems from one platform to another. For example, TopCoder uses rating algorithms (Boudreau et al., 2016), while workers in other freelance platforms are monitored via activity logs. In many crowdwork platforms, such as AMT, the reputation rates are derived from job providers' feedback (Whiting et al., 2016). All reputation systems are designed to provide a reliable indication of the worker's future performance (Whiting et al., 2016) but also to function as an instrument of control that reinforces compliance. However, online reputation scores may also motivate bribes, begging, and threats (Horton and Golden, 2015). For instance, the lack of a reliable reputation system in AMT has led to crowdworkers enhancing their ratings by tacitly or explicitly agreeing to mutually recommend each other (Kittur et al., 2013). 
Therefore, a reputation system that effectively institutes informal social control positively affects the overall control efficiency of crowdwork platform governance by motivating workers to be competent and to comply with the rules of conduct. Thus, we posit that:

\section{P4. Reputation system of workers has a positive effect on control system efficiency.}

\subsubsection{Accountability of Job Providers}

Accountability of job providers refers to the job provider's degree of answerability - that is, the degree to which job providers can be called upon to explain their decisions and actions with regard to submitted work (Table 2). Accountability of job providers functions as an administrative control that motivates job providers' compliant behavior. On AMT and many other crowdwork platforms, job providers can reject work without compensation or explanation, regardless of the actual quality of work (Brawley and Pury, 2016; Deng et al., 2016; Gaikwad et al., 2015). Exceptions include TopCoder, where feedback is provided to all workers, regardless of whether the submitted work is accepted or rejected. Accountability, thus, would require job providers to give a reason for rejecting work and serve as a deterrent to unfair or mistaken rejections.

Therefore, accountability of job providers that effectively institutes administrative control positively affects the overall control efficiency of crowdwork platform governance by motivating job providers to be fair and to comply with the rules of conduct. Thus, we posit that:

\section{P5. Accountability of job providers has a positive effect on control system efficiency.}

\subsubsection{Task Management}

Task management refers to the degree to which a crowdwork platform manages the interdependencies between tasks with different characteristics (e.g., task importance, task diversity, job autonomy, and task clarity) (Deng and Joshi, 2016). Task management includes various activities, such 
as dividing complex tasks into subtasks, managing and merging those subtasks (Kittur et al., 2013), as well as facilitating mutual adjustment among workers performing inter-dependent tasks (Mintzberg, 1980). Task management is particularly crucial in the case of complex tasks with many dependencies and a need for multiple types of skill (Kittur et al., 2013).

Therefore, task management that orchestrates the sequencing and distribution of sub-tasks to willing and able workers (and allows for adjustments to this sequencing and distribution) affects the overall coordination efficiency of crowdwork platform governance by coordinating the pace and flow of work. Thus, we posit that:

P6: Task management has a positive effect on coordination system efficiency.

\subsubsection{Incentive Management}

Incentive management refers to the degree to which crowdwork platform governance manages dependencies between workers' performance and the incentives and rewards available to them. Incentive management is applied to increase worker participation and improve work practices through allocating incentives in a way that benefits both job providers and workers (Kittur et al., 2013; Vakharia and Lease, 2015) beyond the effects of informal and formal control (e.g., reputation and quality control).

Understanding and rewarding desired behavior is a challenge in crowdwork platforms (Kittur et al., 2013). Studies have shown mixed consequences of the impact of financial incentives on the quality of workers' submissions and emphasize the importance of intrinsic motivations, such as nonfinancial awards and credit, importance of tasks, and a collaborative atmosphere (Kittur et al., 2013; Mason and Watts, 2009). Therefore, incentive management also involves job providers' clear communication of desired behaviors. Furthermore, the alignment of these desired behaviors with worker incentives and motivations goes beyond control mechanisms (Kittur et al., 2013; Khanna et al., 2010; Ross et al., 2010). For example, incentive management includes making coordinated decisions about the degree to which 
incentives should be utilized individually or in combination, as well as making decisions about intrinsic vs. extrinsic rewards and managing them for competing effects (Vakharia and Lease, 2015).

Therefore, incentive management that clearly articulates the decisions regarding and distribution of incentives affects the overall coordination efficiency of crowdwork platform governance by aligning the interests of workers and job providers. Thus, we posit that:

\section{P7. Incentive management has a positive effect on coordination system efficiency.}

\subsubsection{Contract Management}

Contract management refers to the degree to which the contracts that govern work arrangements make it possible for the platform to manage interdependencies between job providers and workers. Contract management is a core functionality of the platform that coordinates work planning and the terms of a particular job, including job specifications, deadlines, delivery format, rules of engagement, and dispute resolution (Howcroft and Bergvall-Kåreborn, 2018). Given the lack of a personal relationship (or even a lack of direct communication) between the workers and job provider, the contract serves as the main point of reference for all parties. Contracts that are used to manage and coordinate the work may range in nature and complexity from general terms and conditions (e.g., AMT), to fixed

price boilerplate contracts (e.g., 99design), to contracts with specific rules and conditions (e.g., TopCoder) (Agrawal et al., 2015; Vakharia and Lease, 2015).

Therefore, contract management that explicitly articulates the work arrangements on a platform affects the overall coordination efficiency of crowdwork platform governance by delineating the transactional engagement between job providers and workers. Thus, we posit that:

P8. Contract management has a positive effect on coordination system efficiency. 


\subsection{Crowdwork Platform Governance and Value Creation for Job Providers}

Understanding the conditions for creating value-adding crowdwork poses an important strategic issue for many businesses. In this section, we focus specifically on the value propositions of crowdwork for job providers (Table A.3) and theorize on how crowdwork platform governance effectiveness affects them. As these propositions are largely synthesized from extant research, we have kept this section brief.

\subsubsection{Effective Crowdwork Platform Governance and Quality of Work}

Quality of work refers to the degree to which a work task submitted meets the job specifications (Table 2). While better financial incentives do not necessarily lead to improvements in work quality (Kingsley et al., 2015), it has been shown that detailed and well-made task descriptions (part of task management) and quality control (QC) do increase the quality of work (Harris, 2015). Therefore, we expect that effective crowdwork platform governance - that is, the degree to which the control and coordination of platform resources and activities help to achieve desired results - positively affects the quality of work produced, increasing the value of crowdwork to job providers. Thus, we posit that:

P9. Effective crowdwork platform governance has a positive effect on the quality of work.

\subsubsection{Effective Crowdwork Platform Governance, Cost of Labor and Work Delivery Time}

Cost of labor refers to financial compensation paid by a job provider to crowdworkers in exchange for a work task accomplished, and work delivery time refers to the time it takes for crowdworkers to complete a work task (Table 2). "Fast" and "cheap" have been the main value propositions of crowdwork platforms for job providers since their inception (Gupta et al., 2014; Harris and Srinivasan, 2012; Kittur et al., 2013). Costs associated with crowdwork tend to be considerably lower than those related with more traditional systems of employment, and profit growth is a significant 
motivator for adoption (Bergvall-Kåreborn and Howcroft, 2014; Gupta et al., 2014). Effective crowdwork platform governance (through, for example, quality control) can reduce delivery time, while flexible contract and incentive management can reduce the costs of labor.

Therefore, we expect that effective crowdwork platform governance negatively affects (i.e., reduces) the cost of labor and the time it takes for crowd workers to complete a work task. Thus, we posit that:

P10. Effective crowdwork platform governance has a negative effect on the cost of labor (i.e., cost decrease).

P11. Effective crowdwork platform governance has a negative effect on work delivery time (i.e., delivery time decrease).

\subsubsection{Effective Crowdwork Platform Governance and Scalability of Workforce}

Scalability of workforce refers to the ability of the job provider to adapt the workforce size in response to market demand fluctuations (Table 2). Many freelance platforms appeal to job providers because they provide scalability and flexibility of workforce capacity through access to a large pool of varying levels of skill and experience without employment regulations (Alonso and Mizzaro, 2012; Agrawal et al., 2015; Bergvall-Kåreborn and Howcroft, 2014; Brawley and Pury, 2016; Buhrmester et al., 2011). However, lack of regulations can also lead to unfair treatment of workers and threaten the long-term sustainability of crowdwork (Kittur et al., 2013). Therefore, crowdwork platform governance through accountable providers, well-managed tasks and contracts is likely to attract well-qualified workers. 
Therefore, we expect that effective crowdwork platform governance positively affects the ability of job providers to adapt the workforce size through the pool of crowdworkers available to them on the platform. Thus, we posit that:

P12. Effective crowdwork platform governance has a positive effect on the scalability of the workforce.

\subsubsection{Effective Crowdwork Platform Governance and Reputation of Job Provider}

Reputation of the job provider refers to the general standing of a job provider among the crowdworkers (Table 2). Since most crowdwork platforms currently offer no functionality to capture job provider reputation, crowdworkers tend to construct an idea of the reputation of job providers based on their behavior on the platform, and share this information through other means. For example, in AMT, this information can reach workers via several external forums that crowdworkers use to evaluate job providers (Brawley and Pury, 2016). In many platforms, job providers also do not have to reveal their true identity; thus, their reputation is often entirely dependent on their behavior on the platform. Crowdworkers, particularly more experienced ones, use this information to refuse to collaborate with job providers known to exhibit unfair behavior (Brawley and Pury, 2016; Deng et al., 2016). However, it has also been shown that workers can be appeased when job providers give reasonable justifications for rejecting their work (Chen and Horton, 2016). Thus, effective crowdwork platform governance, through holding job providers accountable, is one way to influence job provider reputation positively.

Therefore, we expect that effective crowdwork platform governance positively affects the reputation of a job provider among the crowdworkers. Thus, we posit that:

P13. Effective crowdwork platform governance has a positive effect on the reputation of job providers. 


\section{Table 2}

\section{Construct Definitions}

\begin{tabular}{ll}
\hline Construct & Definition \\
\hline $\begin{array}{l}\text { Crowdwork Platform } \\
\text { Effectiveness }\end{array}$ & $\begin{array}{l}\text { The degree to which the control and } \\
\text { coordination of platform resources and } \\
\text { activities help to achieve the desired } \\
\text { results (e.g., benefit the stakeholders' } \\
\text { interests) (based on Manner et al., 2012). }\end{array}$ \\
& \\
Control System & \\
Efficiency & $\begin{array}{l}\text { The degree to which crowdwork platform } \\
\text { governance verifies that the activities that } \\
\text { are carried out on the platform (e.g., } \\
\text { workers' and job providers' compliance, } \\
\text { work quality assurance) are within the } \\
\text { desired range and enables taking corrective } \\
\text { actions when needed (based on Fayol, } \\
\text { 1949; Saxton et al., 2013). }\end{array}$
\end{tabular}

Coordination System Efficiency

Quality Control

Reputation System of Workers
Example

TopCoder uses a combination of complex quality controls via algorithms and reviewers, a reputation system based on workers' skills and the number of winning bids, task management through project managers and highly-skilled workers (copilots) ${ }^{6}$ who have a contract with TopCoder, and incentive management (e.g., workshops, promotions) to increase governance effectiveness.

TopCoder's control system can verify crowd workers' identity and take corrective action in the event that workers use fake usernames to increase their reputation.

TopCoder uses a coordination mechanism via project managers and copilots to manage dependencies among complex tasks. These managers and copilots divide tasks into smaller tasks, decide whether the tasks should run in parallel or sequentially, and merge the final accomplished subtasks to deliver the work to the job provider.

Clickworker uses plagiarism checks and peer review to assess the quality of the work produced (Vakharia and Lease, 2015). degree to which a submitted work meets the set requirements or the specification of a job (Agrawal et al., 2015; Wais et al., 2010).

The effectiveness of the reputation scheme, that is, the degree to which the system motivates workers to be competent and to comply with the rules of conduct (Whiting et al., 2016).
Upwork uses ratings ranging from 1 to 5 as the reputation scheme, based on scores given by job providers to workers.

\footnotetext{
${ }^{6}$ Copilots are highly-skilled workers who have received a promotion on the TopCoder platform and now run projects on the platform.
} 


\begin{tabular}{ll}
\hline Construct & Definition \\
\hline $\begin{array}{l}\text { Accountability of Job } \\
\text { Provider }\end{array}$ & $\begin{array}{l}\text { The degree of job providers' answerability } \\
\text { - that is, the degree to which job provider } \\
\text { can be called upon to explain their } \\
\text { decisions and actions with regard to } \\
\text { submitted work (based on Wood and } \\
\text { Winston, 2007). }\end{array}$ \\
& $\begin{array}{l}\text { The degree to which crowdwork platform } \\
\text { governance manages the interdependencies } \\
\text { among tasks (e.g., managing subtasks and } \\
\text { distributing them among workers with } \\
\text { various expertise and capabilities) (Kittur et } \\
\text { al., 2013). }\end{array}$
\end{tabular}

Incentive Management

Contract Management

Quality of Work

Cost of Labor

Work Delivery Time

Scalability of Workforce

The ability of job provider to adapt the workforce size in response to market demand fluctuations (Buhrmester et al., 2011; Alonso and Mizzaro, 2012).
The degree to which the work contracts make it possible for the platform to manage interdependencies between job providers and workers (Agrawal et al., 2015; Vakharia and Lease, 2015).

The degree to which a work task submitted meets the job specifications or the requirements of the job provider (Sarasua and Thimm, 2014).

Financial compensation paid by a job provider to crowdworkers in exchange for a work task accomplished (Agrawal et al., 2015; Kittur et al., 2013).

The time it takes for crowd workers to complete a work task (Gupta et al., 2014; Rzeszotarski and Kittur, 2012).
Example

TopCoder provides feedback from reviewers and job providers to workers who are interested in the reasons for rejection. However, in AMT job providers can reject work without giving a reason (Brawley and Pury, 2016; Deng et al., 2016).

Clickworker platform manages tasks according to the job provider's requirements and compatibility of the worker. TopCoder uses project managers and highly-skilled workers to decompose tasks and run them in parallel or sequentially.

AMT job providers may provide extra incentives to workers in the form of a reward payment (Harris, 2015). TopCoder awards prizes to winners (Kittur et al., 2013).
AMT facilitates routine work based on a set fee but does not provide a contract. However, most platforms that facilitate creative work, like Upwork, support two types of contracts: hourly wage and fixed price (Agrawal et al., 2015; Vakharia and Lease, 2015).

AMT, 99designs and most other crowdwork platforms measure the quality of work only based on job provider's acceptance or rejection of the work.

AMT's average cost of labor is $\$ 2 /$ hour.

AMT's crowdworkers accept and submit a task in 39 minutes on average (Brawley and Pury, 2016).

TopCoder has more than one million registered crowdworkers ${ }^{7}$, and AMT has about 500,000 registered crowdworkers worldwide (Difallah et al., 2018). The larger

\footnotetext{
${ }^{7}$ https://www.topcoder.com/blog/1-million-members-strong/ (retrieved 16 October 2018)
} 


\begin{tabular}{|c|c|c|}
\hline Construct & Definition & Example \\
\hline & & $\begin{array}{l}\text { the pool of workers, the better job providers } \\
\text { are able to adapt their workforce size to } \\
\text { market demand (Alonso and Mizaaro, 2012). }\end{array}$ \\
\hline $\begin{array}{l}\text { Reputation of Job } \\
\text { Provider }\end{array}$ & $\begin{array}{l}\text { The general standing of a job provider } \\
\text { among the crowdworkers (Brawley and } \\
\text { Pury, 2016). }\end{array}$ & $\begin{array}{l}\text { AMT's external forums provide information } \\
\text { about job providers' behaviors through } \\
\text { workers' review and discussion of job } \\
\text { providers and tasks. }\end{array}$ \\
\hline Degree of Centralization & $\begin{array}{l}\text { The extent to which crowdwork platform } \\
\text { governance (i.e., the control and } \\
\text { coordination systems) is centralized, } \\
\text { ranging from centralized to decentralized } \\
\text { (Azfar et al., 2001; Scholz, 2016). }\end{array}$ & $\begin{array}{l}\text { AMT and Upwork use centralized } \\
\text { governance. There are no examples of } \\
\text { completely decentralized crowdwork } \\
\text { platform governance based on the literature } \\
\text { review. }\end{array}$ \\
\hline Degree of Routinization & $\begin{array}{l}\text { The extent to which the tasks are } \\
\text { accomplished through a repetitive work } \\
\text { process that follows explicitly prescribed } \\
\text { simple instructions and requires minimal } \\
\text { individual creativity from workers } \\
\text { (Buettner 2015; Margaryan, 2016). }\end{array}$ & $\begin{array}{l}\text { AMT tasks are more routine (e.g., tagging } \\
\text { pictures and filling surveys), whereas } \\
\text { Upwork tasks are more creative (e.g., web } \\
\text { development and graphic design) } \\
\text { (Margaryan, 2016). }\end{array}$ \\
\hline
\end{tabular}

\subsection{Contingencies of Crowdwork Platform Governance}

Most platforms, for both routine and creative crowdwork, govern through centralized schemes (Table A.2), with a few exceptions in which governance is done through a hybrid model (e.g., some specific drivers of governance, such as reputation and quality control, are managed in a decentralized manner). For instance, Whiting et al. (2016) designed and developed crowd guilds, which are decentralized groups of workers who certify the quality of each other's work collectively via a doubleblind peer assessment. Most studies of crowdwork also focus on routine work platforms, like AMT, while there are only a few studies on platforms for creative work, like Upwork (Table A.2). Nonetheless, as highlighted earlier, recent research is increasingly suggesting that many of the challenges of crowdwork could be eliminated, and its benefits enhanced, if it were to go beyond traditional centralized arrangements by drawing on ideas of cooperativism and worker-owned and -managed platforms 
(Gaikwad et al., 2015; Scholz, 2016). The emergence of new technical architectures can help to realize these seemingly utopic decentralized governance schemes (Tate et al., 2017). Similarly, with microtask crowdwork platforms such as AMT suffering from a bad reputation and an exodus of workers (Deng et al., 2016), job providers must increasingly consider whether crowdwork is also suitable for more complex and creative tasks, as well as how to best govern creative crowdwork. For these reasons, we theorize on how the degree of centralization of platform governance and the degree of routinization of crowdwork may change some of the relationships outlined above.

\subsubsection{Degree of Centralization of Crowdwork Platform Governance}

The degree of centralization refers to the extent to which the crowdwork platform governance (i.e., the control and coordination systems) is centralized (Table 2). As such, we expect that the degree of centralization will moderate the effect of control and coordination mechanisms on crowdwork platform governance effectiveness.

With regard to control, centralized governance lowers costs and permits more control by upper management (in this case, platform owners and job providers), whereas decentralized governance delegates more control to workers (Baschab and Piot, 2007). By removing hierarchical power structures, decentralization of governance can decrease the misuse of power (Azfar et al., 2001). For example, blockchain technology can enable swift dispute resolution through the transparency provided by an audit trail of all transactions (i.e., job submission time, job assessment outcome); in addition, when the terms of a job are met, a payment can be made automatically via a smart contract that cannot be manipulated by any party (Tate et al., 2017). Thus, non-payment for accepted work (i.e., wage theft) would become inconceivable. Part of job provider accountability would, in essence, be coded into the platform architecture. In the current centralized systems, like AMT, wage theft happens regularly (Irani, 2015b) and exposes a clear deficiency in the control system (lack of job provider accountability). 
Therefore, we posit that verification and corrective action (control) will have a relatively stronger positive effect on crowdwork platform governance effectiveness in centralized platforms, because verification and corrective action provide the mechanism that forces all stakeholders to abide by the rules and curtails misuse of power. Conversely, verification and corrective action will have a relatively weaker positive effect on crowdwork platform governance effectiveness in decentralized platforms, because decentralization of control requires that all stakeholders abide by their collectivelycreated rules, some of which may be coded into the platform (Azfar et al., 2001). Thus:

P14a. Degree of centralization has a positive moderation effect on the relationship between the control system and crowdwork platform governance effectiveness.

Centralization usually improves coordination, including resource allocation, incentive and contract management. Knowledge management and distribution of tasks and rewards can be easier and faster, as the basic questions of 'who does what, when, and what do they get for it' are decided centrally, thus not requiring time-consuming discussions or consensus (Whiting et al., 2016). Conversely, decentralized governance creates coordination challenges and demands for laborious consensus-based decision making. Recent research (Tate et al., 2017) suggests that blockchain-based decentralized contract management can result in flexibility (the terms of smart contracts are, by definition, programmable) but also irreversibility and networked integrity (once a contract is published, any changes in it will be observable to the network, immutable, and applied equally). These many benefits, however, do not change the facts that (1) setting up such a smart contract system is necessary in a decentralized system (whereas a centralized system can function without contracts, with the intermediary platform serving as the 'trusted' third party arbitrator), and (2) setting up such a system will take some effort and, thus, will incur costs on the platform (and indirectly on job providers and workers).

Therefore, we expect that the management of dependencies (coordination) will have a relatively stronger positive effect on crowdwork platform governance effectiveness in decentralized platforms, because the 
management of dependencies between workers and job providers, tasks and incentives is essential in aligning stakeholder interests and actions in decentralized governance. Conversely, when coordination is centralized, everyone's interests and actions are aligned with those of the central actor through control; thus, less coordination effort is needed (Azfar et al., 2001). Thus:

P14b. Degree of centralization has a negative moderation effect on the relationship between the coordination system and crowdwork platform governance effectiveness.

\subsubsection{Degree of Routinization}

The degree of routinization refers to the extent to which crowdwork tasks are accomplished through a repetitive work process that follows explicitly prescribed simple instructions and requires minimal individual creativity from workers (Table 2). Governance challenges have been found in both routine and creative crowdwork platforms (Brawley and Pury, 2016; Deng et al., 2016; Schörpf et al., 2017). For example, in AMT, the lack of job provider accountability has spawned external forums for information sharing among workers and high turn-over (Brawley and Pury, 2016; Deng et al., 2016). In creative crowdwork platforms, such as Upwork and 99designs, workers depend heavily on job provider ratings (e.g., to have access to higher paid jobs) and, thus, engage in the strategic selection of jobs to build up their reputation. At the same time, creative crowdworkers feel that they often do the work out of interest, rather than financial incentives ("how low will I go?" often being the operating principle on price) (Schörpf et al., 2017). These issues are likely to have an effect on the quality of work, cost of labor, and other outcomes that job providers value. As such, we expect that the degree of routinization of work tasks will moderate the effect of crowdwork platform governance effectiveness on the value delivered to job providers.

With regard to the quality of work, it is clear that the routine work of repetitive tasks with "clear definitions" (Buettner, 2015) will (a) be easier to evaluate and (b) vary less in the quality of the output. 
Therefore, we posit that effective control and coordination are likely to have only a limited impact on improving quality:

P15a. Degree of routinization has a negative moderation effect on the relationship between crowdwork platform governance effectiveness and quality of work.

With regard to cost of labor and work delivery time, routine crowdwork also varies little in terms of the financial compensation provided (average $\$ 2 /$ hour on AMT) and also in terms of the time it takes to accomplish microtasks (average of 39 minutes on AMT; see Table 2). Thus, because in routine work the costs are already low and the average delivery time is short, we argue that effective crowdwork platform governance has inherently a limited effect and consequently limited impact on these outcomes. Conversely, in creative work, effective crowdwork platform governance (e.g., well-defined contracts, well-functioning QC) can reduce costs of labor and delivery time more significantly. Evidence suggests that in creative platforms (e.g., Upwork), financial compensation for different jobs varies significantly, as does the complexity of tasks (Schörpf et al., 2017). In sum, we suggest that:

P15b. Degree of routinization has a negative moderation effect on the relationship between crowdwork platform governance effectiveness and cost of labor.

P15c. Degree of routinization has a negative moderation effect on the relationship between crowdwork platform governance effectiveness and work delivery time.

With regard to the scalability of workforce - that is, the ability of job provider to adapt the workforce size by having access to an adaptable pool of crowdworkers with varying skills (Alonso and Mizzaro, 2012; Agrawal, et al, 2015; Brawley and Pury, 2016; Buhrmester et al., 2011) - we expect that the workforce available for routine tasks is inherently more scalable because of the sheer size of the 
potential pool. While TopCoder is estimated to have more workers than AMT (about one million versus 500,000; see Table 2), TopCoder's workers are divided into programmers, designers and data scientists with different skills and areas of expertise. Thus, whereas all AMT's workers can, in principle, perform nearly any of the micro tasks posted on the platform, on TopCoder, worker and task types are more difficult to match. Therefore effective crowdwork platform governance is likely to have only a limited impact on the scalability of workforce provided by routine crowdwork platforms, while it is likely to enhance the scalability afforded by creative platforms. Thus, we posit that:

P15d. Degree of routinization has a negative moderation effect on the relationship between crowdwork platform governance effectiveness and the scalability of the workforce.

Finally, with regard to the reputation of job providers, it has been shown that accountability of job providers influences the behavior of workers doing both routine and creative crowdwork. Thus, we expect that effective crowdwork platform governance, in terms of holding job providers accountable, positively affects job provider reputation regardless of the degree of routinization (Brawley and Pury, 2016; Schörpf et al., 2017). Therefore, we do not posit a moderation effect in this case.

\section{Implications for the Future of Value-Adding Crowdwork}

Crowdwork is a new form of digitally mediated employment that involves the performance of tasks online for a fee by distributed independent workers. Crowdwork is performed through platforms, which function as intermediaries that orchestrate and facilitate the work through a set of governance mechanisms that control and coordinate the work process. As a novel socio-technical phenomenon that has the capacity to change the nature of work organization and to provide strategic value to workers and job providers alike, crowdwork is disrupting contemporary working arrangements (Forman et al., 2014) 
while also creating significant negative backlash, particularly because of reported unfair treatment of workers (Deng et al., 2016; Kittur et al., 2013). Thus, in this paper we set out to better understand how crowdwork platform governance delivers on this promise of strategic value to job providers, while also providing fair working conditions.

The contribution of this paper lies in advancing the conceptualization of crowdwork platform governance. The paper provides a coherent theoretical grounding for describing and investigating crowdwork platform governance arrangements through control and coordination mechanisms. We also highlight the role of the degree of centralization of platform governance and the degree of routinization of work as critical moderators of crowdwork platform governance effectiveness and its impact on job provider benefit. Furthermore, we offer new theoretical insights that lead to the consideration of additional value propositions for job providers, especially with regard to the quality of work and reputation of job providers, which are not often discussed in current literature on crowdwork platforms. In sum, building on prior crowdwork platforms research, this paper extends the construct of governance in the context of crowdwork platforms, discusses its relevance and benefits to job providers, and provides substantive directions for future research in the form of a set of propositions. We leave it to future research to extend this theoretical work by operationalizing and testing the proposed model. Next, we consider the theoretical and practical implications of the proposed model.

First, by unpacking crowdwork platform governance into two key mechanisms (control and coordination), we contribute to a better theoretical understanding of the crowdwork governance phenomenon. As highlighted earlier, prior research has often discussed governance issues in crowdwork platforms, but definitions have been broad and systematic investigations into governance scant (Nickerson et al., 2017). In particular, while control is often mentioned in the platform and crowd governance literature (e.g., Tiwana, et al., 2010), coordination is rarely mentioned. Most extant crowdwork literature talks of "management" (Deng et al., 2016), but the concept remains vague. Thus, this paper makes headway by deriving the definition and significance of the coordination mechanisms 
in crowdwork platform governance. While control is obviously important in all governance, we think coordination is particularly significant in crowdwork, because managing dependencies (e.g., between tasks, workers and job providers, incentives and performance) is key when work is temporary, largescale, distributed, and mediated. Future research could further focus on the empirical examination of the coordination mechanism and its functioning in different crowdwork arrangements. Coordination is also of particular importance in decentralized crowdwork platform governance, as explained below.

The moderating effect of the degree of centralization highlights that the control mechanism is more critical to effective centralized crowdwork platform governance, whereas the coordination mechanism is more critical to effective decentralized crowdwork platform governance. Control, in terms of verification and corrective action, will have a stronger positive impact on centralized crowdwork platform governance effectiveness, which is more likely to suffer from power imbalances and power misuse (Azfar et al., 2001; Zyskind et al., 2015). Conversely, coordination, in terms of managing dependencies, will have a stronger positive impact on decentralized crowdwork platform governance effectiveness, which is more likely to suffer from disconnects, perturbations, process breakdowns, and laborious demands for consensus-based decision-making (Whiting et al., 2016). This also highlights that while the promise of decentralized platform architecture is becoming palpable with new technologies like blockchain (Tate et al., 2017), governance challenges, particularly those related to coordination, will likely increase in the short-term. Thus, if the future of crowdwork is decentralized, coordination (and the task, incentive and contract management that drive it) will be the key to ensuring its success and strategic value to job providers.

From a strategic perspective, maintaining the quality and scalability of highly-skilled workforce through better governance can improve organizational dynamic capabilities (Teece et al., 1997) through the ability to: (1) adjust their production capacity on the go to meet the ebbs and flows of the market demand (Lepak and Snell, 1999), (2) execute pilots on innovation projects without disrupting the work of the permanent staff, or on emergent innovation that requires ad hoc skills, unavailable in the 
organization (Kittur et al., 2013), and (3) reach out to the "wisdom of the crowds" (Majchrzak and Malhotra, 2013). These three operational improvements are known to drive strategic value in terms of increasing organizational agility and generative capacity.

Second, the conceptual model helps us to theorize on what we consider the future of crowdwork. Based on trends in society and technology, as well as initial lessons learned from crowdwork arrangements reported in the literature, we expect that crowdwork will evolve beyond the current centralized governance arrangements (Gaikwad et al., 2015; Scholz, 2016; Tate et al., 2017) and will also have to become suitable for increasingly complex and creative tasks (Schörpf et al., 2017). Crowdwork has long since expanded beyond microtasks into citizen journalism, motor vehicle design, text editing, and similar work that requires ingenuity and professional expertise. These shifts, however, are also important to consider in governance, because, as the conceptual model shows, the degree of routinization of work impacts the extent to which effective crowdwork platform governance can influence the value that crowdwork generates. Specifically, the moderating effect of the degree of routinization on the relationships between crowdwork platform governance and the value propositions highlights that effective crowdwork platform governance is critical to overall value generation in nonroutine work. Effective control and coordination are expected to have a strong positive impact on work quality, to reduce costs further, and to improve work delivery time in creative (i.e., non-routine) crowdwork platforms. Thus, we expect that effective crowdwork platform governance will become increasingly important as job providers increasingly move to crowdwork arrangements for more complex and creative tasks. However, with routine crowdwork platforms suffering from unfair working conditions, high turnover and bad reputation (Deng et al., 2016; Kittur et al., 2013), their long-term sustainability is also in question and can be improved through better governance.

We summarize these thoughts about the future of value-adding crowdwork into a twodimensional framework (Table 3), which we hope can serve as a guide for both researchers and practitioners (especially job providers). 


\section{Table 3}

Future of Value-Adding Crowdwork

\begin{tabular}{l|ll}
\hline & Routine Work & Creative Work \\
\hline $\begin{array}{l}\text { Centralized Crowdwork } \\
\text { Platform Governance }\end{array}$ & Digital Sweatshop & Talent Factory \\
$\begin{array}{l}\text { Decentralized Crowdwork } \\
\text { Platform Governance }\end{array}$ & Day-labor Marketplace & Talent Marketplace \\
\hline
\end{tabular}

In Table 3, we provide four metaphors for different crowdwork arrangements based on the degree of centralization of crowdwork platform governance and the degree of routinization of work tasks. The digital sweatshop (Pittman and Sheehan, 2016) and talent factory metaphors dominate the current crowdwork platforms that are characterized by centralized governance. The digital sweatshop refers to crowdwork sites like AMT, which operate with the principle of keeping costs down and profits up with little regard for the working conditions created for workers or the tools provided for job providers to extract value from crowdwork (e.g., no quality control scheme). This operating principle relies on outsourcing simple jobs to low-skilled, cheap labor with few alternative job opportunities. Conversely, the talent factory refers to crowdwork platforms that deal with more creative and complex work (e.g., Upwork, TopCoder). While talent implies value and the need for nurturing, the talent factory metaphor emphasizes the Tayloristic and functional attitude towards work organization (Donini et al., 2017). The talent factory metaphor emphasizes the ability of a platform to deliver, on-demand, the right individuals with the right skills (Hewitt, 2009; Ready and Conger, 2007). In contrast to these metaphors, we suggest that future crowdwork platforms, which will be increasingly characterized by decentralized governance, will evoke day-labor and talent marketplace metaphors. While the operating principles of routine and creative work are still in place, both metaphors denote a shift in power; in these scenarios, both low- and high-skilled workers have more control over whom they sell their skills to at market price (Lee, 2014). 
These four metaphors offer a useful starting point for job providers and platform owners to strategically think about work organization and platform design. Centrally governed platforms served as a stepping stone into establishing early forms of crowdwork. However, the emergence of decentralized governance - through, for example, blockchain technologies - is paving the way for the evolution of crowdwork platforms into a more cost-effective and equitable work ecosystem.

\section{Conclusion}

In conclusion, building on this theory review and conceptual model development, we provided a deeper insight into crowdwork platform governance, which could be used to inform employers, platform designers, and policymakers who have the power to forge a more attractive future of crowdwork for both job providers and crowdworkers. We hope to demonstrate that one avenue for such a shift lies in revisiting our assumptions concerning what crowdwork arrangements look like and rethinking the design and role of platforms in crowdwork. Particularly in the domain of low-skilled work, the platform can play a more prominent role in the integration of labor than is desirable; that is, it can describe and direct the work using Tayloristic hetero-direction (Donini et al., 2017). We suggest that addressing these issues should go beyond improving existing platform designs (such as updating AMT) to consider entirely novel, alternative platform designs. In summary, we are cautiously optimistic about the future potential of crowdwork to contribute to inclusion, equitable wages and flexible work arrangements for workers, while organizations can keep costs of labor in check and smoothly adjust to the ebb and flow in the demand for labor. 


\section{References}

Agrawal, A., Horton, J., Lacetera, N., \& Lyons, E., 2015. Digitization and the contract labor market: A research agenda, in: Goldfarb, A., Greenstein, S.M., \& Tucker, C.E. (Eds.), Economic Analysis of the Digital Economy. University of Chicago Press, Chicago, IL, pp. 219-250.

Aiello, L., D'Ascenzo, F., Gatti, M., \& Rossetti, F., 2015. A new evolution of IT: The integration between lean enterprise and crowdworking. A theoretical model, in: Agrifoglio, R., Caporarello, L., Magni, M., \& Za, S. (Eds.), Re-shaping Organizations through Digital and Social Innovation. Luiss University Press, Rome, Italy, pp. 315-326.

Al-Ani, A. \& Stumpp, S., 2016. Rebalancing interests and power structures on crowdworking platforms. Internet Pol. Rev. 5 (2), 1-19.

Alonso, O., \& Mizzaro, S., 2012. Using crowdsourcing for TREC relevance assessment. Info. Proc. \& Manage. 48 (6), 1053-1066.

Azfar, O., Kahkonen, S., \& Meagher, P., 2001. Conditions for effective decentralized governance: A synthesis of research findings. IRIS Center Working Paper, University of Maryland. Retrieved from:

http://www1.worldbank.org/publicsector/learningprogram/Decentralization/ConditionsEffective .pdf.

Atzori, M., 2015. Blockchain technology and decentralized governance: Is the state still necessary? Retrieved from: https://papers.ssrn.com/sol3/papers.cfm?abstract_id=2709713.

Baschab, J., \& Piot, J., 2007. The executive's guide to information technology ( $2^{\text {nd }}$ ed.). John Wiley \& Sons, Hoboken, NJ.

Bergvall-Kåreborn, B., \& Howcroft, D., 2014. Amazon Mechanical Turk and the commodification of labour. New Tech., Work and Employ. 29 (3), 213-223.

Bigham, J. P., Williams, K., Banerjee, N., \& Zimmerman, J., 2017. Scopist: Building a skill ladder into crowd transcription. In Proceedings of the 14th Web for All Conference on The Future of Accessible Work, Perth, Australia. ACM, Article no. 2.

Brawley, A. M., \& Pury, C. L., 2016. Work experiences on MTurk: Job satisfaction, turnover, and information sharing. Comp. in Hum. Beh. 54 (1), 531-546.

Brown, A. E., \& Grant, G. G., 2005. Framing the frameworks: A review of IT governance research. Comm. of the Assoc. for Info. Sys. 15 (1), 38.

Boudreau, K. J., Lakhani, K. R., \& Menietti, M., 2016. Performance responses to competition across skill levels in rank-order tournaments: field evidence and implications for tournament design. The RAND J. of Econ. 47 (1), 140-165.

Buettner, R., 2015. A systematic literature review of crowdsourcing research from a human resource management perspective. In Proceedings of the 48th Hawaii International Conference of System Sciences (HICSS), Washington, DC, USA. IEEE, 4609-4618.

Buhrmester, M., Kwang, T., \& Gosling, S. D., 2011. Amazon's Mechanical Turk: A new source of inexpensive, yet high-quality, data? Perspectives on Psych. Sci. 6 (1), 3-5.

Celis, L. E., Reddy, S. P., Singh, I. P., \& Vaya, S., 2016. Assignment techniques for crowdsourcing sensitive tasks. In Proceedings of the 19th ACM Conference on Computer-Supported Cooperative Work \& Social Computing, San Francisco, CA, USA. ACM, 836-847. 
Chatterjee, A., Varshney, L. R., \& Vishwanath, S., 2015. Work capacity of freelance markets: Fundamental limits and decentralized schemes. In Computer Communications (INFOCOM), 2015 IEEE Conference, Hong Kong, China. IEEE, 1769-1777.

Chandler, D., \& Kapelner, A., 2013. Breaking monotony with meaning: Motivation in crowdsourcing markets. J. of Econ. Beh. \& Org. 90, 123-133. https://doi.org/10.1016/j.jebo.2013.03.003.

Chen, C., Cheng, S. F., Gunawan, A., Misra, A., Dasgupta, K., \& Chander, D., 2014. Traccs: a framework for trajectory-aware coordinated urban crowd-sourcing. In Proceedings of the Second AAAI Conference on Human Computation and Crowdsourcing, Pittsburgh, PA, USA. AAAI, 641-650.

Chen, D. L., \& Horton, J. J., 2016. Are online labor markets spot markets for tasks? A field experiment on the behavioral response to wage cuts. Info. Sys. Res. 27 (2), 403-423.

Crowston, K., 1997. A coordination theory approach to organizational process design. Org. Sci. 8 (2), 157-175.

Deng, X., \& Joshi, K. D., 2016. Why individuals participate in micro-task crowdsourcing work environment: Revealing crowdworkers' perceptions. J. of the Assoc. for Info. Sys. 17 (10), 648.

Deng, X., Joshi, K. D., \& Galliers, R. D., 2016. The duality of empowerment and marginalization in microtask crowdsourcing: Giving voice to the less powerful through value sensitive design. MIS Quart. 40 (2), 279-302.

De Stefano, V., 2016. The rise of the" just-in time workforce": On demand work, crowdwork, and labor protection in the" gig economy". Comp. Labor Law and Pol. J. 37 (3), 461-471.

Difallah, D., Filatova, E., \& Ipeirotis, P., 2018. Demographics and dynamics of Mechanical Turk workers. In Proceedings of the Eleventh ACM International Conference on Web Search and Data Mining, Marina Del Rey, CA USA. ACM, 135-143.

Donini, A., et al., 2017. Towards collective protections for crowdworkers: Italy, Spain and France in the EU context. Transfer: Europ. Rev. of Labour and Res. 23 (2), 207-223.

Durward, D., Blohm, I., \& Leimeister, J. M., 2016. Is there PAPA in crowd work? A literature review on ethical dimensions in crowdsourcing. In Proceedings of IEEE International Conference on Internet of People, Toulouse, France. IEEE, 823-832.

Eisenhardt, K. M., 1985. Control: Organizational and economic approaches. Man. Sci. 31 (2), 134-149.

Fayol, H., 1949. General and industrial management. Pitman Publishing, New York, NY.

Fieseler, C., Bucher, E., \& Hoffmann, C. P., 2017. Unfairness by design? The perceived fairness of digital labor on crowdworking platforms. J. of Bus. Ethics. https://doi.org/10.1007/s10551-017$3607-2$

Finnerty, A., Kucherbaev, P., Tranquillini, S., \& Convertino, G., 2013. Keep it simple: Reward and task design in crowdsourcing. In Proceedings of the Biannual Conference of the Italian Chapter of SIGCHI, Trento, Italy. ACM, Article No. 14.

Forman, C., King, J. L., \& Lyytinen, K., 2014. Information, technology, and the changing nature of work. Info. Sys. Res. 25 (4), 789-795.

Gaikwad, S. N., Morina, D., Nistala, R., Agarwal, M., Cossette, A., Bhanu, R., .. \& Mithal, A., 2015. Daemo: A self-governed crowdsourcing marketplace. In Adjunct Proceedings of the 28th Annual ACM Symposium on User Interface Software \& Technology, Charlotte, NC, USA. ACM, 101102. 
Gawer, A., 2014. Bridging differing perspectives on technological platforms: Toward an integrative framework. Res. Pol. 43 (7), 1239-1249.

Gillespie, T., 2017. Governance of and by platforms, in: Burgess, J., Marwick, A., \& Poell, T. (Eds.), The SAGE Handbook of Social Media. SAGE Publications Inc., Thousand Oaks, CA, USA. 254278.

Goel, G., Nikzad, A., \& Singla, A., 2013. Matching workers expertise with tasks: Incentives in heterogeneous crowdsourcing markets. Presented at NIPS Workshop on Crowdsourcing, Lake Tahoe, NV, USA, December 2013.

Gould, S. J., Cox, A. L., \& Brumby, D. P., 2015. Task lockouts induce crowdworkers to switch to other activities. In Proceedings of the 33rd Annual ACM Conference on Human Factors in Computing Systems, Seoul, Republic of Korea. ACM, 1785-1790.

Gould, S. J., Cox, A. L., \& Brumby, D. P., 2016. Diminished control in crowdsourcing: an investigation of crowdworker multitasking behavior. ACM Trans. on Comp.-Hum. Int., 23 (3), Article No. 19.

Gray, M. L., Suri, S., Ali, S. S., \& Kulkarni, D., 2016. The crowd is a collaborative network. In Proceedings of the 19th ACM Conference on Computer-Supported Cooperative Work \& Social Computing, San Francisco, CA, USA. ACM, 134-147.

Greengard, S., 2011. Following the crowd. Comm. of the ACM, 54 (2), 20-22.

Gupta, N., Crabtree, A., Rodden, T., Martin, D., \& O’Neill, J., 2014. Understanding Indian crowdworkers. In Proceedings of the 2014 Conference on Computer Supported Cooperative Work (CSCW), Baltimore, MD, USA. ACM.

Hagiu, A., \& Spulber, D., 2013. First-party content and coordination in two-sided markets. Man. Sci. 59 (4), 933-949.

Hagiu, A., \& Wright, J., 2015. Multi-sided platforms. Int. J. of Industrial Org., 43, 162-174. Retrieved from: http://nrs.harvard.edu/urn-3:HUL.InstRepos:15786564.

Harris, C. G., \& Srinivasan, P., 2012. With a little help from the crowd: Receiving unauthorized academic assistance through online labor markets. In Proceedings of the 2012 International Conference on Social Computing, Washington, DC, USA. IEEE, 904-909.

Harris, C., \& Wu, C., 2014. Using tri-reference point theory to evaluate risk attitude and the effects of financial incentives in a gamified crowdsourcing task. J. of Bus. Econ. 84 (3), 281-302.

Harris, C. G., 2015. The effects of pay-to-quit incentives on crowdworker task quality. In Proceedings of the 2015 ACM Conference on Computer Supported Cooperative Work \& Social Computing, Vancouver, Canada. ACM, 1801-1812.

Hata, K., Krishna, R., Fei-Fei, L., \& Bernstein, M. S., 2017. A glimpse far into the future: Understanding long-term crowd worker accuracy. In Proceedings of the 2017 ACM Conference on Computer Supported Cooperative Work and Social Computing, Portland, OR, USA. ACM, 889-901.

Hein, A., Schreieck, M., Wiesche, M., \& Krcmar, H., 2016. Multiple-case analysis on governance mechanisms of multi-sided platforms. Presented at Multikonferenz Wirtschaftsinformatik, Ilmenau, Germany.

Hewitt, S. D., 2009. The secrets of successful succession planning in the new age wave. Industrial and Commerc. Train. 41 (4), 181-186.

Horton, J. J., \& Chilton, L. B., 2010. The labor economics of paid crowdsourcing. In Proceedings of the 2010 ACM Conference on Electronic Commerce, Cambridge, MA, USA. ACM, 209-218. 
Horton, J., \& Golden, J., 2015. Reputation inflation: Evidence from an online labor market. NYU,

Working Paper. Retrieved from:

https://pdfs.semanticscholar.org/59d6/e24bf80c01384d5ce8a64e1582208b8b7072.pdf.

Howcroft, D., \& Bergvall-Kåreborn, B., 2018. A typology of crowdwork platforms. Work, Employment and Soc. Advanced online publication, https://doi.org/10.1177/0950017018760136.

Ipeirotis, P. G., 2010. Analyzing the Amazon Mechanical Turk marketplace. XRDS: Crossroads, The ACM Magazine for Students. 17 (2), 16-21.

Irani, L. C., \& Silberman, M., 2013. Turkopticon: Interrupting worker invisibility in Amazon Mechanical Turk. In Proceedings of the SIGCHI Conference on Human Factors in Computing Systems, Paris, France. ACM, 611-620.

Irani, L., 2015a. The cultural work of microwork. New Med. \& Soc. 17 (5), 720-739.

Irani, L., 2015b. Difference and dependence among digital workers: The case of Amazon Mechanical Turk. South Atlantic Quart. 114 (1), 225-234.

Jianhan, S., Phua, V. W. I., \& Varshney, L. R., 2016. Distributed estimation via paid crowd work. In Proceedings of 2016 IEEE International Conference on Acoustics, Speech and Signal Processing (ICASSP), Shanghai, China. IEEE, 6200-6204.

Kaufmann, N., Schulze, T., \& Veit, D., 2011. More than fun and money. Worker motivation in crowdsourcing - A study on Mechanical Turk. In proceedings of the 2011 American Conference on Information Systems, Detroit, MI, USA. AMCIS, Article No. 11, 1-11.

Khanna, S., Ratan, A., Davis, J., \& Thies, W., 2010. Evaluating and improving the usability of Mechanical Turk for low-income workers in India. In Proceedings of the First ACM Symposium on Computing for Development, London, UK. ACM, Article No. 12.

King, J. L., 1983. Centralized versus decentralized computing: organizational considerations and management options. ACM Computing Surveys (CSUR), 15 (4), 319-349.

Kingsley, S. C., Gray, M. L., \& Suri, S., 2015. Accounting for market frictions and power asymmetries in online labor markets. Pol. \& Internet. 7 (4), 383-400.

Kirsch, L. S., 1997. Portfolios of control modes and IS project management. Info. Sys. Res. 8 (3), 215239.

Kittur, A., Nickerson, J. V., Bernstein, M., Gerber, E., Shaw, A., Zimmerman, J., Lease, M., \& Horton, J., 2013. The future of crowd work. In Proceedings of the 2013 Conference on Computer Supported Cooperative Work Companion, San Antonio, TX, USA. ACM, 1301-1318.

LaPlante, R., Silberman, M. S., \& Metall, I., 2016. In crowd worker forums: Worker ownership, governance, and work outcomes. Presented at WebSci16, Hannover, Germany.

Lee, S., 2014. Policing wage theft in the day labor market. UC Irvine Law Rev. 4 (2), 655-678.

Lepak, D. P., \& Snell, S. A. (1999). The human resource architecture: Toward a theory of human capital allocation and development. Academy of management review, 24(1), 31-48.

Liu, S. B., 2014. Crisis crowdsourcing framework: Designing strategic configurations of crowdsourcing for the emergency management domain. Comp. Supported Coop. Work (CSCW), 23 (4-6), 389443.

Ma, X., Khansa, L., \& Hou, J., 2016. Toward a contextual theory of turnover intention in online crowdworking. In Proceedings of 2016 International conference on Information System (ICIS), Dublin, Ireland. AIS. Retrieved from: https://aisel.aisnet.org/icis2016. 
Majchrzak, A., \& Malhotra, A. (2013). Towards an information systems perspective and research agenda on crowdsourcing for innovation. The Journal of Strategic Information Systems, 22(4), 257-268.

Malone, T. W., \& Crowston, K., 1990. What is coordination theory and how can it help design cooperative work systems? In Proceedings of the 1990 ACM conference on Computer-Supported Cooperative Work, Los Angeles, CA, USA. ACM, 357-370.

Malone, T. W., \& Crowston, K., 1994. The interdisciplinary study of coordination. ACM Computing Surveys (CSUR). 26 (1), 87-119.

Manner, J., Nienaber, D., Schermann, M., \& Krcmar, H., 2012. Governance for mobile service platforms: A literature review and research agenda. In Proceedings of the International Conference on Mobile Business (ICMB), Delft, The Netherlands. AIS. Retrieved from: http://aisel.aisnet.org/icmb2012.

Margaryan, A., 2016. Understanding crowdworkers' learning practices. Presented at the 2016 Internet, Policy and Politics Conference, Oxford, UK.

Marr, B., 2016. Crowdworking: Is your job heading for the cloud? Forbes, October 18, 2016. Retrieved from: https://www.forbes.com/sites/bernardmarr/2016/10/18/crowdworking-is-your-jobheading-for-the-cloud/\#72b3a2e639d6.

Mason, W., \& Suri, S., 2012. Conducting behavioral research on Amazon's Mechanical Turk. Beh. Res. Methods. 44 (1), 1-23.

Mason, W., \& Watts, D. J., 2009. Financial incentives and the performance of crowds. In Proceedings of the ACM SIGKDD Workshop on Human Computation, Paris, France. ACM, 77-85.

Milland, K., 2016. A Mechanical Turk worker's perspective. J. of Media Ethics. 31 (4), 263-264.

Mintzberg, H., 1980. Structure in 5's: A synthesis of the research on organization design. Man. Sci. 26 (3), 322-341.

Nickerson, J. V., 2014. Crowd work and collective learning, in: Littlejohn, A., \& Margaryan, A. (Eds.), Technology-enhanced professional learning: processes, practices, and tools. Routledge, New York, NY, pp. 39-49.

Nickerson, J. A., Wuebker, R., \& Zenger, T., 2017. Problems, theories, and governing the crowd. Strat. Org. 15 (2), 275-288.

Paré, G., Trudel, M. C., Jaana, M., \& Kitsiou, S., 2015. Synthesizing information systems knowledge: A typology of literature reviews. Info. \& Man. 52 (2), 183-199.

Pittman, M., \& Sheehan, K., 2016. Amazon's Mechanical Turk a digital sweatshop? Transparency and accountability in crowdsourced online research. J. of Media Ethics. 31 (4), 260-262.

Ready, D. A., \& Conger, J. A., 2007. Make your company a talent factory. Harvard Bus. Rev. 85 (6), 68-77.

Rimmer, S. H., 2016. Australian experiments in creative governance, regionalism, and plurilateralism. Int. J. 71 (4), 630-650.

Ross, J., Irani, L., Silberman, M., Zaldivar, A., \& Tomlinson, B., 2010. Who are the crowdworkers? Shifting demographics in Mechanical Turk. In CHI'10 Extended Abstracts on Human Factors in Computing Systems. ACM, 2863-2872.

Rowe, F., 2014. What literature review is not: diversity, boundaries and recommendations. European J. of Info. Sys. 23 (3), 241-255. 
Ryu, H., \& Lease, M., 2011. Crowdworker filtering with support vector machine. Proceedings of the Assoc. for Info. Sci. and Tech. 48 (1), 1-4.

Rzeszotarski, J., \& Kittur, A., 2012. CrowdScape: interactively visualizing user behavior and output. In Proceedings of the 25th Annual ACM Symposium on User Interface Software and Technology, Cambridge, MA, USA. ACM, 55-62.

Sarasua, C., \& Thimm, M., 2014. Crowd work CV: Recognition for micro work. In Proceedings of International Conference on Social Informatics, Barcelona, Spain. Springer, 429-437.

Saxton, G. D., Oh, O., \& Kishore, R., 2013. Rules of crowdsourcing: Models, issues, and systems of control. Info. Sys. Man. 30 (1), 2-20.

Schmidt, F., 2017. Digital labour markets in the platform economy. Mapping the political challenges of crowd work and gig work. Friedrich-Ebert-Stiftung. Retrieved from: http://library.fes.de/pdffiles/wiso/13164.pdf.

Scholz, T., 2016. Platform cooperativism. Challenging the corporate sharing economy. Rosa Luxemburg Stiftung. Retrieved from: http://www.rosalux-nyc.org/wpcontent/files_mf/scholz_platformcoop_5.9.2016.pdf.

Schörpf, P., Flecker, J., Schönauer, A., \& Eichmann, H., 2017. Triangular love-hate: management and control in creative crowdworking. New Tech., Work and Employment. 32 (1), 43-58.

Schreieck, M., Wiesche, M., \& Krcmar, H., 2016. Design and governance of platform ecosystems-key concepts and issues for future research. In Proceedings of European Conference on Information System (ECIS), Istanbul, Turkey. AIS. Retrieved from: https://aisel.aisnet.org/ecis2016.

Smith, H. J., Dinev, T., \& Xu, H., 2011. Information privacy research: an interdisciplinary review. MIS Quart. 35 (4), 989-1016.

Tate, M., Johnstone, D., \& Fielt, E., 2017. Ethical issues around crowdwork: How can blockchain technology help? In Proceedings of 2017 Australasian Conference on Information Systems, Hobart, Australia (ACIS).

Teece, D. J., Pisano, G., \& Shuen, A. (1997). Dynamic Capabilities and Strategic Management. Strategic Management Journal, 18(7), 509-533

Tiwana, A., Konsynski, B., \& Bush, A. A., 2010. Research commentary-Platform evolution: Coevolution of platform architecture, governance, and environmental dynamics. Info. Sys. Res. 21 (4), 675-687.

Vakharia, D., \& Lease, M., 2015. Beyond Mechanical Turk: An analysis of paid crowd work platforms. Proceedings of the iConference 2015, Newport Beach, CA, USA. https://www.ideals.illinois.edu/handle/2142/73278

Wais, P., Lingamneni, S., Cook, D., Fennell, J., Goldenberg, B., Lubarov, D., Marin, D., \& Simons, H., 2010. Towards building a high-quality workforce with Mechanical Turk. Presented at the Computational Social Science and the Wisdom of Crowds Workshop (NIPS), Whistler, Canada.

Webster, J., \& Watson, R. T., 2002. Analyzing the past to prepare for the future: Writing a literature review. MIS Quart. 26 (2), xiii-xxiii.

Whiting, M. E., Gamage, D., Gaikwad, S. S., Gilbee, A., Goyal, S., Ballav, A., ... \& Sarma, T. S., 2016. Crowd guilds: Worker-led reputation and feedback on crowdsourcing platforms. In Proceedings of the 2017 ACM Conference on Computer Supported Cooperative Work and Social Computing, Portland, OR, USA. ACM: 1902-1913. 
Wohlin, C., 2014. Guidelines for snowballing in systematic literature studies and a replication in software engineering. In Proceedings of the 18th International Conference on Evaluation and Assessment in Software Engineering, London, UK. ACM, Article No. 38.

Wood, J. A., \& Winston, B. E., 2007. Development of three scales to measure leader accountability. Leadership \& Org. Dev. J. 28 (2), 167-185.

Woodman R.W., Sawyer J.E., \& Griffin R.W., 1993. Toward a theory of organizational creativity. Acad. of Man. Rev. 18 (2), 293-321.

Ye, H. J., \& Kankanhalli, A., 2017. Solvers' participation in crowdsourcing platforms: Examining the impacts of trust, and benefit and cost factors. The J. of Strateg. Info. Sys. 26 (2), 101-117.

Xu, Y., Li, Q., Min, X., Cui, L., Xiao, Z., \& Kong, L., 2016. E-commerce blockchain consensus mechanism for supporting high-throughput and real-time transaction. In Proceedings of the International Conference on Collaborative Computing: Networking, Applications and Worksharing, Beijing, China. Springer, 490-496.

Zyskowski, K., Morris, M. R., Bigham, J. P., Gray, M. L., \& Kane, S. K., 2015. Accessible crowdwork? Understanding the value in and challenge of microtask employment for people with disabilities. In Proceedings of the 18th ACM Conference on Computer Supported Cooperative Work \& Social Computing, Vancouver, Canada. ACM, 1682-1693.

Zyskind, G., Nathan, O., \& Pentland, A., 2015. Enigma: Decentralized computation platform with guaranteed privacy. Computing Research Repository (CoRR). Retrieved from: https://arxiv.org/abs/1506.03471. 


\section{Appendix}

\section{Table A.1}

Overview of Crowdwork Literature Foci

\begin{tabular}{|c|c|c|c|c|c|}
\hline Perspective & Author(s) & Description & 裉 & 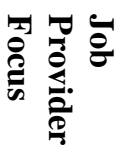 & 承 \\
\hline \multirow{4}{*}{$\begin{array}{l}\text { Holistic } \\
\text { This perspective } \\
\text { includes papers } \\
\text { that have } \\
\text { investigated } \\
\text { crowdwork } \\
\text { platforms based } \\
\text { on all three } \\
\text { agents' concerns: } \\
\text { workers, job } \\
\text { providers, and } \\
\text { platforms }\end{array}$} & $\begin{array}{l}\text { Kittur et al. } \\
(2013)\end{array}$ & $\begin{array}{l}\text { Outlines a general framework for the future of } \\
\text { crowdwork that is fair and meaningful for workers and } \\
\text { produces high-quality work for job providers }\end{array}$ & \multirow{4}{*}{+} & \multirow{4}{*}{+} & \multirow{4}{*}{+} \\
\hline & $\begin{array}{l}\text { Deng et al. } \\
(2016)\end{array}$ & $\begin{array}{l}\text { Identifies crowdworker values (access, autonomy, } \\
\text { fairness, transparency, communication, security, } \\
\text { accountability, making an impact, and dignity); offers } \\
\text { guidelines for job providers and AMT design }\end{array}$ & & & \\
\hline & $\begin{array}{l}\text { Rzeszotarski } \\
\text { and Kittur } \\
(2012)\end{array}$ & $\begin{array}{l}\text { Presents CrowdScape, a system that supports the } \\
\text { human evaluation of complex crowdwork through } \\
\text { interactive visualization and mixed initiative machine } \\
\text { learning }\end{array}$ & & & \\
\hline & $\begin{array}{l}\text { Gould et al. } \\
\text { (2016) }\end{array}$ & $\begin{array}{l}\text { Tests an intervention that encourages workers to stay } \\
\text { focused on the job provider's task after multitasking } \\
\text { has been detected }\end{array}$ & & & \\
\hline \multirow{5}{*}{$\begin{array}{l}\text { Worker \& } \\
\text { Platform } \\
\text { This perspective } \\
\text { includes papers } \\
\text { that have } \\
\text { investigated } \\
\text { crowdwork } \\
\text { platforms based } \\
\text { on the concerns of } \\
\text { workers and } \\
\text { platforms }\end{array}$} & $\begin{array}{l}\text { Zyskowski } \\
\text { et al. }\end{array}$ & $\begin{array}{l}\text { Examines how to make crowdwork accessible to } \\
\text { crowdworkers with disabilities }\end{array}$ & \multirow{5}{*}{+} & \multirow{5}{*}{ - } & \multirow{5}{*}{+} \\
\hline & $\begin{array}{l}\text { Sarasua } \\
\text { and Thimm } \\
(2014)\end{array}$ & $\begin{array}{l}\text { Examines the benefits of profiling crowdworkers; } \\
\text { introduces the idea of crowdworker CV (and its } \\
\text { dimensions) }\end{array}$ & & & \\
\hline & $\begin{array}{l}\text { Ye and } \\
\text { Kankanhalli } \\
(2017)\end{array}$ & $\begin{array}{l}\text { Presents a model to explain the impacts of benefit and } \\
\text { cost factors as well as trust on solver participation } \\
\text { behavior in crowdsourcing }\end{array}$ & & & \\
\hline & $\begin{array}{l}\text { Deng and } \\
\text { Joshi }(2016)\end{array}$ & $\begin{array}{l}\text { Explores the characteristics of crowdworkers, } \\
\text { crowdsourcing jobs, and the crowdwork environment } \\
\text { that collectively drives the crowdworkers to } \\
\text { participate in open source work }\end{array}$ & & & \\
\hline & $\begin{array}{l}\text { Durward et } \\
\text { al. }(2016)\end{array}$ & $\begin{array}{l}\text { Investigates ethical issues in crowdwork (e.g., } \\
\text { privacy, accessibility) and the impact of ethical issues } \\
\text { on the sustainability of crowdwork for the worker }\end{array}$ & & & \\
\hline
\end{tabular}




\begin{tabular}{|c|c|c|c|c|c|}
\hline $\begin{array}{l}\text { Worker \& Job } \\
\text { Provider } \\
\text { This perspective }\end{array}$ & $\begin{array}{l}\text { Brawley } \\
\text { and Pury } \\
(2016)\end{array}$ & $\begin{array}{l}\text { Studies AMT worker job satisfaction, information } \\
\text { sharing and turnover; also examines best/worst } \\
\text { behaviors by job providers }\end{array}$ & & & \\
\hline $\begin{array}{l}\text { investigated } \\
\text { crowdwork } \\
\text { platforms based } \\
\text { on the concerns of } \\
\text { the workers and } \\
\text { job providers }\end{array}$ & $\begin{array}{l}\text { Chen and } \\
\text { Horton } \\
\text { (2016) }\end{array}$ & $\begin{array}{l}\text { Investigates the impact of wage cuts on } \\
\text { crowdworkers' behavior }\end{array}$ & + & + & - \\
\hline $\begin{array}{l}\text { Single Agent } \\
\text { This perspective }\end{array}$ & $\begin{array}{l}\text { Donini et } \\
\text { al. (2017) }\end{array}$ & $\begin{array}{l}\text { Considers the collective rights of independent digital } \\
\text { contractors }\end{array}$ & + & - & - \\
\hline $\begin{array}{l}\text { includes papers } \\
\text { that have } \\
\text { investigated } \\
\text { crowdwork }\end{array}$ & $\begin{array}{l}\text { Horton and } \\
\text { Chilton } \\
(2010)\end{array}$ & $\begin{array}{l}\text { Presents a model of workers supplying labor to paid } \\
\text { crowdsourcing projects; estimates a worker's } \\
\text { reservation wage (i.e., the smallest wage a worker is } \\
\text { willing to accept for a task) }\end{array}$ & + & - & - \\
\hline $\begin{array}{l}\text { on a single } \\
\text { agent's } \\
\text { perspective }\end{array}$ & $\begin{array}{l}\text { Horton and } \\
\text { Golden } \\
(2015)\end{array}$ & $\begin{array}{l}\text { Investigates factors that inflate reputation; also, } \\
\text { proposes that aggregate private feedback scores from } \\
\text { job providers to workers can be used by job providers } \\
\text { to screen workers and make hiring decisions }\end{array}$ & - & + & - \\
\hline
\end{tabular}


Table A.2

Crowdwork Platform Governance Mechanisms (by degree of centralization of governance and degree of routinization of work)

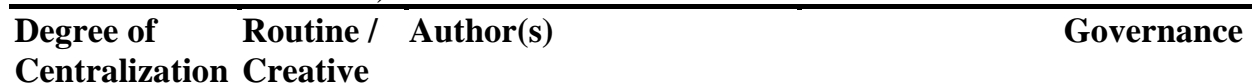

\begin{tabular}{|c|c|c|c|c|c|}
\hline \multicolumn{3}{|c|}{$\begin{array}{l}\text { Coordination System } \\
\text { Efficiency }\end{array}$} & \multicolumn{3}{|c|}{$\begin{array}{l}\text { Control System } \\
\text { Efficiency }\end{array}$} \\
\hline 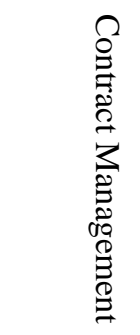 & 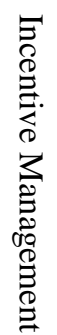 & 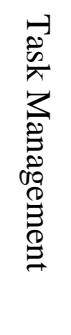 & 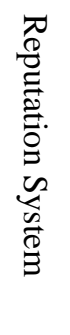 & 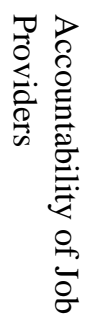 & 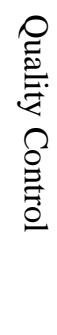 \\
\hline
\end{tabular}

\begin{tabular}{|c|c|c|c|c|c|c|c|c|}
\hline \multirow[t]{13}{*}{ Centralized } & \multirow[t]{13}{*}{ Routine } & Fieseler et al. (2017) & + & + & + & + & + & + \\
\hline & & Harris (2015) & - & + & + & + & - & + \\
\hline & & Kittur et al. (2013) & - & + & + & + & - & - \\
\hline & & Hata et al. (2017) & + & - & + & - & - & + \\
\hline & & Deng et al. (2016) & - & + & - & + & + & - \\
\hline & & Brawley and Pury (2016) & - & + & - & + & - & - \\
\hline & & $\begin{array}{l}\text { Rzeszotarski and Kittur } \\
\text { (2012) }\end{array}$ & - & - & + & - & - & + \\
\hline & & Gould et al. (2016) & - & - & + & - & - & + \\
\hline & & Gupta et al. (2014) & - & - & - & + & - & + \\
\hline & & Horton and Chilton (2010) & - & + & - & - & - & - \\
\hline & & Deng and Joshi (2016) & - & + & - & - & - & - \\
\hline & & Chen and Horton (2016) & + & - & - & - & - & - \\
\hline & & Ipeirotis (2010) & - & - & + & - & - & - \\
\hline & \multirow[t]{2}{*}{ Creative } & Agrawal et al. (2015) & + & + & - & - & - & + \\
\hline & & Horton and Golden (2015) & - & + & - & + & - & - \\
\hline & $\begin{array}{l}\text { Routine } \\
\&\end{array}$ & Al-Ani and Stumpp (2016) & - & + & - & + & - & - \\
\hline & Creative & Durward et al. (2016) & + & - & - & - & - & + \\
\hline
\end{tabular}




\begin{tabular}{|c|c|c|c|c|c|c|c|c|}
\hline \multirow{3}{*}{$\begin{array}{l}\text { Degree of } \\
\text { Centralization }\end{array}$} & \multirow{3}{*}{$\begin{array}{l}\text { Routine / } \\
\text { Creative }\end{array}$} & \multirow[t]{3}{*}{ Author(s) } & \multicolumn{6}{|c|}{ Governance } \\
\hline & & & \multicolumn{3}{|c|}{$\begin{array}{l}\text { Coordination System } \\
\text { Efficiency }\end{array}$} & \multicolumn{3}{|c|}{$\begin{array}{l}\text { Control System } \\
\text { Efficiency }\end{array}$} \\
\hline & & & 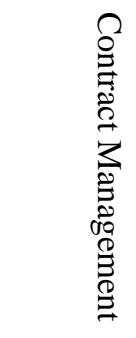 & 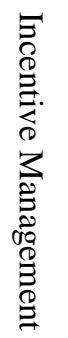 & 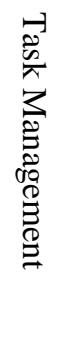 & 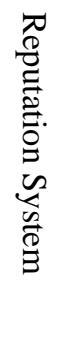 & 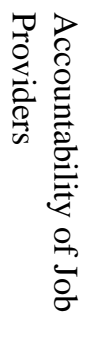 & 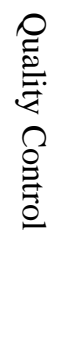 \\
\hline \multirow[t]{3}{*}{ Hybrid } & Routine & Whiting et al. (2016) & - & + & + & + & - & + \\
\hline & & Aiello et al. (2015) & - & + & + & + & - & + \\
\hline & $\begin{array}{c}\text { Routine } \\
\& \\
\text { Creative }\end{array}$ & Chatterjee et al. (2015) & - & - & + & + & - & + \\
\hline
\end{tabular}


Table A.3

Value of Crowdwork Platform Governance for Job Providers

\begin{tabular}{|c|c|c|c|c|c|}
\hline \multirow[t]{2}{*}{ Author(s) } & \multicolumn{5}{|c|}{ Value of Crowdwork Platform Governance for Job Providers } \\
\hline & 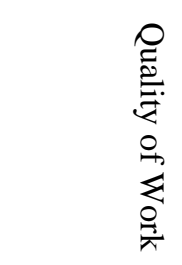 & \begin{tabular}{l}
0 \\
0 \\
0 \\
0 \\
$\stackrel{0}{0}$ \\
\multirow{0}{0}{} \\
0
\end{tabular} & 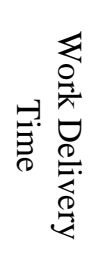 & 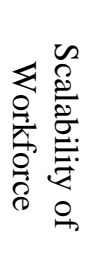 & 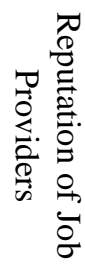 \\
\hline Kittur et al. (2013) & + & - & + & + & + \\
\hline Bergvall-Kåreborn and Howcroft (2014) & - & + & - & + & - \\
\hline Brawley and Pury (2016) & - & + & - & - & + \\
\hline Agrawal et al. (2015) & - & + & - & + & - \\
\hline Deng and Joshi (2016) & - & + & - & - & - \\
\hline Chen and Horton (2016) & - & + & - & - & - \\
\hline Durward et al. (2016) & - & + & - & - & - \\
\hline Al-Ani and Stumpp (2016) & - & + & - & + & - \\
\hline Rzeszotarski and Kittur (2012) & - & - & + & + & - \\
\hline Gupta et al. (2014) & - & + & + & - & - \\
\hline Harris (2015) & + & + & + & - & - \\
\hline Gould et al. (2016) & - & - & + & + & - \\
\hline Buettner (2015) & + & - & + & + & - \\
\hline
\end{tabular}




\section{Table A.4}

Other Literature Informing Tables A.1, A.2 and A.3

\begin{tabular}{ll}
\hline Other Sources & Tables Informed \\
\hline Chandler and Kapelner (2013) & Tables A2 \& A3 \\
Gould et al. (2015) & Tables A1, A2 \& A3 \\
Ryu and Lease (2011) & Tables A1 \& A2 \\
Jianhan et al. (2016) & Tables A1, A2 \& A3 \\
Mason and Suri (2012) & Tables A1, A2 \&A3 \\
Bigham et al. (2017) & Tables A1, A2 \&A3 \\
Finnerty et al. (2013) & Tables A2 \& A3 \\
Harris and Srinivasan (2012) & Tables A1, A2 \& A3 \\
Harris and Wu (2014) & Tables A1, A2 \& A3 \\
Celis et al. (2016) & Tables A1 \& A2 \\
Irani and Silberman (2013) & Tables A1 \& A2 \\
Irani (2015a, b) & Tables A1, A2 \& A3 \\
De Stefano (2016) & Tables A1, A2 \& A3 \\
LaPlante et al. (2016) & Tables A1 \& A2 \\
Smith et al. (2011) & Tables A1\& A2 \\
Kaufmann et al. (2011) & Tables A1, A2 \& A3 A1 \& A2 \\
Milland (2016) & \\
\hline
\end{tabular}

